\title{
Structure-Guided Identification of DNMT3B Inhibitors
}

\author{
Ana S. Newton, ${ }^{\dagger}$ John C. Faver, ${ }^{\dagger}$ Goran Micevic,${ }^{\S}$ Viswanathan Muthusamy, ${ }^{\zeta}$ Shalley N.
}

Kudalkar, ${ }^{\dagger}$ Nicole Bertoletti, ${ }^{\ddagger}$ Karen S. Anderson, ${ }^{\ddagger}$ Marcus W. Bosenberg, ${ }^{\S, \xi}$ and William L. Jorgensen $^{\dagger, *}$

'Department of Chemistry, Yale University, New Haven, Connecticut 06520-8107; Departments of Dermatology, ${ }^{\S}$ Medicine, ${ }^{\zeta}$ Pharmacology, ${ }^{\ddagger}$ Pathology, ${ }^{\xi}$ and Immunobiology, ${ }^{\xi}$ Yale University School of Medicine, New Haven, CT 06520-8066.

\section{Supporting Information}

\section{Table of Contents}

1. Experimental Details $\quad$ SI2

1.1 Homology Model $\quad$ SI2

1.2 Database $\quad$ SI2

1.3 Virtual Screening $\quad$ SI2

$\begin{array}{ll}1.4 \text { Purchased Compounds } & \text { SI2 }\end{array}$

1.5 Kinetic Fluorogenic Assay $\quad$ SI3

1.6 Drone General Information SI3

1.6.1 Protein expression and purification - DNMT3B catalytic domain SI3

1.6.2 Enzymatic reaction time points and sample clean-up SI4

1.6.3 Inhibition experiment with $\mathbf{3 3 h}$ SI5

1.6.4 Quantifying \% product and extraction of observed rate SI5

2. General Procedure for Preparation of Analogues of Compound $11 \quad$ SI5

2.1 General Information $\quad$ SI5

2.2 Synthesis of $N$-methylmethanamine derivatives $\quad$ SI6

2.3 Synthesis of 3-(3-iodophenyl)propanoic acid $\quad$ SI6

2.4 Synthesis of 3-(3-(1H-indol-2-yl)phenyl)propanoic acid $\quad$ SI7

$\begin{array}{ll}2.5 \text { Synthesis of compounds 29a-29c } & \text { SI7 }\end{array}$

2.6 Amidation SI8

2.7 Synthesis of compounds 32a-32d and 33a-33j $\quad$ SI10

$\begin{array}{lr}\text { Table S1 } & \text { SI14 }\end{array}$

Table S2 $\quad$ SI15

3. References $\quad$ SI16 


\title{
1. Experimental Details
}

\author{
1.1 Homology Model
}

DNMT3B homology model was constructed from the crystal structure of DNMT3A (PDBID: 2QRV) ${ }^{1}$, which is $81 \%$ identical and $96 \%$ similar in the highly conserved catalytic domain. Sequence alignment was done through Prime ${ }^{2}$, and isoform 1 (identifier: Q9UBC3-1) [http://www.uniprot.org/uniprot/Q9UBC3.fasta] DNMT3B_human, was used for model building. The aligned sequence of query (Q9UBC3) and template (2QRV_A) (Fig. S1) showed 76\% identities (fraction of amino acids that are the same between a pair of sequences, after their alignment). Homology structure was built using the aligned template and the refinement loop between ARG827-GLN842 (2QRV) was performed using Prime-Refinement ${ }^{2}$. All the steric clashes were refined through minimization using OPLS2005 force field ${ }^{3}$.

\subsection{Database}

ZINC12 database ${ }^{4}$, was used. The subset selected for the virtual screening was the drug-like that contains more than 10 million compounds (10,637,968 - 2012-08-22), which has been filtered in accord with Lipinski's rules 5 . The compounds were processed with LigPrep (v 2.5) to generate three-dimensional structures with multiple conformers.

\subsection{Virtual Screening}

The constructed homology model of DNMT3B was employed in the docking calculations using GLIDE 5.7.109 (Schrödinger, LLC) for a rapid structure-based filtering of ZINC drug-like subset. The scoring grids were centered in the binding site obtained through the homology model. The box size (in $\AA$ ): $20 \times 20 \times 20$, covers the catalytic pocket and cofactor site. All structures were docked and scored using the Glide standard precision (SP) mode. ${ }^{6}$ After visual inspection of the top-ranked 1000 compounds, 248 compounds were selected and redocked with GOLD ${ }^{7}$ version 5.1 and Glide $\mathrm{XP}^{8}$. For GOLD, all atoms within $10 \AA$ of the binding site were included. Default parameters were used. A maximum of 10 docking runs per molecule were performed allowing early termination, if the top three solutions are within $1.5 \AA$ A RMS deviation of each other. Poses were evaluated with GoldScore and rescored with ChemPLP. The selection was based on the docking scores, on favourable interactions with the receptor and also on the predictions of physical properties from QikProp9 ${ }^{9}$ Molecules containing unwanted structural features were removed (readily hydrolysable and/ or containing highly electrophilic functional groups).

\subsection{Purchased Compounds}

The identities of all purchased compounds were confirmed by ${ }^{1} \mathrm{H}$ NMR and high-resolution mass spectrometry; purity was normally $>95 \%$ as shown by high-performance liquid chromatography. 
1.5 Kinetic Fluorogenic Assay

Recombinant DNMT1 and DNMT3B enzymes (SKU SRP0126 and SRP0166) were purchased from Sigma-Aldrich (Darmstadt, Germany). DNMT activity was measured by a kinetic fluorogenic assay, adapted from the original description by Wood et al. ${ }^{10}$ as modifications by Syeda et al. ${ }^{11}$ and Fagan et al. ${ }^{12}$ The DNA substrate is an internally quenched hairpin oligonucleotide (self-complementary) that contains CpG sites, which are DNMT targets. Upon methylation, a methylation-specific endonuclease GlaI cleaves the oligonucleotide resulting in de-quenching and fluorescent signal. DNA methylation reaction mixture (final volume 50uL) was composed of $100 \mathrm{nM}$ of oligonucleotide substrate (5'-FAM-CCTATGCGmCATCAGTTTTCTGATGmCGmCAT AGG-3'-IowaBlack, IDT DNA), 1.6 mM SAM (NewEnglandBiolabs), $200 \mathrm{ng}$ of DNMT3Bc-DNMT3Lc (SIGMA SRP0166), 2 U GlaI (SibEnzyme) and 1-100 $\mu \mathrm{M}$ of inhibitor in a total volume of $80 \mu \mathrm{L}$ of DNMT assay buffer (50 $\mathrm{mM} \mathrm{NaCl}, 10 \mathrm{mM}$ Tris- $\mathrm{HCl}, 10 \mathrm{mM} \mathrm{MgCl}, 100 \mu \mathrm{g} / \mathrm{ml} \mathrm{BSA}, \mathrm{pH}$ 7.9). The reaction mixture was added to wells of 96-well black plates (Thermo) and fluorescence was recorded using a $485 \mathrm{~nm}$ excitation and $535 \mathrm{~nm}$ emission wavelength in kinetic mode at $37^{\circ} \mathrm{C}$ for 30 minutes on a SpectraMax (Molecular Devices) instrument. $\mathrm{mC}$ denotes methylation cytosine.

DNMT activity and inhibition was also validated using a colorimetric EquiQuick DNMT Activity/Inhibition Assay Ultra Kit (P-3009-96) per the manufacture's instruction (Epigentek).

\subsection{DRONE General Information}

All DNA oligonucleotides used in this study were ordered and HPLC or PAGE purified (Integrated DNA Technologies, Coralville, IA). For enzyme reactions and DNA extractions, a pre-mixed solution of 25:24:1 phenolchloroform-isoamyl alcohol mixture was used (Cat. \# 77617, Sigma-Aldrich, St. Louis, MO). For UHPLC separations, all experiments were conducted on the Agilent 1290 Infinity II LC System (Agilent Technologies, Santa Clara, CA). Individual gradients were performed using the InfinityLab Poroshell $120 \mathrm{HPH}-\mathrm{C} 18,2.1$ x $100 \mathrm{~mm}, 1.9 \mu \mathrm{m}$ diameter (Part \# 695675-702, Agilent Technologies, Santa Clara, CA). Absorbance detection was conducted on the 1260 DAD WR (Part \# G7115A, Agilent Technologies, Santa Clara, CA). Fluorescence detection was conducted on the 1260 FLD Spectra (Part \# G7121B, Agilent Technologies, Santa Clara, CA). Reagents used for mobile phase include trimethylamine HPLC grade (Cat. \#O4884-100, Fisher Scientific, Hampton, NH), hexafluoroisopropanol (Cat. \#105228, Sigma-Aldrich, St. Louis, MO), and methanol (Cat. \#MX0488, Merck Millipore, Burlington, MA).

\subsubsection{Protein expression and purification - DNMT3B catalytic domain}

The plasmids pET11 and pET28a containing the P561-E853 fragment coding sequences of the human gene DNMT3B and the E177-L386 fragment DNMT3L, respectively, were obtained from ARVYS (Trumbull, CT USA). The pETbased plasmids containing the coding sequences of DNMT3B with a N-terminal His10-tag containing a TEV (Tobacco Etch Virus) protease cleavage site, and DNMT3L with a N-terminal FLAG tag, were co-transformed into Rosetta 2 
(DE3) pLysS competent cells. The transformed bacteria cells were grown overnight in $100 \mathrm{~mL}$ of LB medium containing $100 \mu \mathrm{g} / \mathrm{mL}$ of ampicillin and $30 \mu \mathrm{g} / \mathrm{mL}$ of kanamycin at $37^{\circ} \mathrm{C}$. Subsequently, $15 \mathrm{~mL}$ of the overnight culture were transferred in $1 \mathrm{~L}$ of the aforementioned medium and allowed to grow at $37{ }^{\circ} \mathrm{C}$ until an $\mathrm{OD}_{600}$ of 0.3 was reached and the culture was cooled to $16^{\circ} \mathrm{C}$. When the culture reached the $\mathrm{OD}_{600}$ of 0.6 the cells were induced with $0.5 \mathrm{mM}$ IPTG. The bacteria cells were harvested after 4 hours by centrifugation and stored at $-80^{\circ} \mathrm{C}$ overnight before proceeding with the purification.

The cell pellet was resuspended in a buffer containing $50 \mathrm{mM}$ Tris, $500 \mathrm{mM} \mathrm{NaCl}, 0.5 \mathrm{mM}$ TCEP, $10 \mathrm{mM}$ Imidazole, 10 mM MgSO $4,0.5 \%$ (v/v) Triton X-100, 10\% (v/v) glycerol and cOmplet Protease Inhibitor Cocktail Tablet (Roche, Germany) adjusted at a pH of 7.4. The cells were disrupted with a high-pressure homogenizer and the obtained lysate was centrifuged at $30000 \mathrm{~g}$ for $1 \mathrm{~h}$ at $4^{\circ} \mathrm{C}$. The supernatant was applied to a Ni-NTA column, and a washing step was applied with a buffer containing $50 \mathrm{mM}$ Tris, $500 \mathrm{mM} \mathrm{NaCl}, 0.5 \mathrm{mM}$ TCEP, $20 \mathrm{mM}$ Imidazole, 10 $\mathrm{mM} \mathrm{MgSO} 4,5 \mathrm{mM}$ ATP and 10\% (v/v) glycerol to remove non-specifically bound protein. The target protein was eluted using a linear gradient of imidazole from $20 \mathrm{mM}$ to $600 \mathrm{mM}$. TEV protease was added to the eluted protein mixture to cleave the $\mathrm{N}-8 \mathrm{His}$-tag and it was dialyzed overnight at $4{ }^{\circ} \mathrm{C}$ to reduce the imidazole concentration in the sample (50 mM Tris, $500 \mathrm{mM} \mathrm{NaCl}, 0.5 \mathrm{mM}$ TCEP and 10\% (v/v) glycerol adjusted at a pH of 7.4). A second Ni-NTA column was used for separation of the TEV protease from the DNMT3B/3L protein complex. In this step the protein was collected from the flow through of the column, while the TEV protease remained on the column. With the goal to increase the purity of the protein, an additional purification step, using a size exclusion chromatography (Superdex 200 16/60) was performed with a running buffer comprising $50 \mathrm{mM}$ Tris, $300 \mathrm{mM} \mathrm{NaCl}, 0.5 \mathrm{mM}$ TCEP and 5\% (v/v) glycerol. To the isolated target protein, was added a final concentration of glycerol of $20 \%$. The protein solution was flash-frozen in liquid nitrogen and stored at $-80^{\circ} \mathrm{C}$.

\subsubsection{Enzymatic reaction time points and sample clean-up}

All enzymatic reactions were conducted with a final oligonucleotide concentration of $5 \mu \mathrm{M}$, a final protein concentration of $5 \mu \mathrm{M}$ and a final concentration of $50 \mu \mathrm{M}$ of S-adenosyl Methionine (SAM) at $37^{\circ} \mathrm{C}$ at a total volume of $40 \mu$. For DNMT3B reactions, reactions were incubated in a buffer of $50 \mathrm{mM}$ Tris $\mathrm{pH} 8.0,50 \mathrm{mM} \mathrm{NaCl}$, and $0.1 \%$ beta-mercaptoethanol. Each timepoint was collected by quenching with an equal volume of 25:24:1 phenolchloroform-isoamyl alcohol mixture. Following termination of reactions, the individual timepoints were centrifuged for 1 minute at 16,000 $\mathrm{x} \mathrm{g} \mathrm{RCF}$, and the top aqueous layer was isolated. The resulting sample was then dialyzed using the Slide-A-Lyzer ${ }^{\mathrm{TM}}$ MINI dialysis device against $4 \mathrm{~L}$ of double distilled water over three hours $(1 \mathrm{~L}$ water 1 hour, 1 $\mathrm{L}$ water 1 hour, $2 \mathrm{~L}$ water 1 hour). Subsequently, the samples were dried down with a speed vacuum centrifuge before reconstitution with $40 \mu \mathrm{l}$ water. A total of $10 \mu \mathrm{L}$ (10 pg DNA) was injected into the UHPLC for analysis. 


\subsubsection{Inhibition experiment with $\mathbf{3 3 h}$}

Varying concentrations of $\mathbf{3 3 h}$ was incubated with $5 \mu \mathrm{M}$ of DNMT3B, in the above mentioned buffer mixture for 15 minutes on ice to allow for maximal binding before addition of $5 \mu \mathrm{M}$ substrate and $50 \mu \mathrm{M}$ of SAM to initiate the reaction at $37^{\circ} \mathrm{C}$. The reaction was subsequently quenched after overnight and cleaned up as described previously for UHPLC analysis.

\subsubsection{Quantifying \% product and extraction of observed rate}

To quantify $\%$ product turned over, we employ the formula, $\%$ product $=($ AUC product/AUC reactant + AUC product $)$

$* 100 . \%$ product for each timepoint is calculated using this method to generate product formation over time. An observed single turnover rate constant $\mathrm{k}_{\mathrm{obs}}$ was extracted by fitting to a single exponential curve, Percent product $=$ $A\left(1-e^{-k o b s * t i m e}\right)$, in which $\mathrm{A}$ is the maximum $\%$ product.

\section{General Procedure for Preparation of Analogues of Compound 11}

\subsection{General Information}

Reagents and solvents were obtained from commercial supplies and used without further purification. Reactions were monitored by thin-layer chromatography (TLC) using Merck pre-coated silica gel plates (analytical, $\mathrm{SiO}_{2}-60, \mathrm{~F}_{254}$ ). TLC plates were visualized under U.V. light $(254 \mathrm{~nm})$. Organic solutions were concentrated under reduced pressure on a Büchi rotary evaporator. flash column chromatography was performed on a Combiflash ${ }^{\circledR} \mathrm{Rf}+$ (Teledyne Isco, Lincoln, NE) with RediSep RF GOLD ${ }^{\circledR}$ (silica gel, particle size 20-40 $\mu \mathrm{m}$ ) prepared cartridges. Nuclear magnetic resonance (NMR) spectra were recorded either on Agilent $\mathrm{DD}_{2} 400\left({ }^{1} \mathrm{H}\right.$ NMR, ${ }^{13} \mathrm{C}$ NMR recorded at 400, and 101 MHz, respectively), an Agilent $\mathrm{DD}_{2} 500\left({ }^{1} \mathrm{H}\right.$ NMR, ${ }^{13} \mathrm{C}$ NMR recorded at 500, and $126 \mathrm{MHz}$, respectively). All spectra were recorded at room temperature, $62^{\circ} \mathrm{C}$ or $80^{\circ} \mathrm{C}$ as noted. Chemical shifts are reported in ppm relative to deuterated solvent as an internal standard $\left(\delta_{\mathrm{H}}\right.$ DMSO- $d_{6} 2.50 \mathrm{ppm}, \delta_{\mathrm{C}} \mathrm{DMSO}-d_{6} 39.52 \mathrm{ppm} ; \delta_{\mathrm{H}}$ Methanol- $d_{6} 3.31 \mathrm{ppm}, \delta_{\mathrm{C}}$ Methanol- $d_{6} 49.00 \mathrm{ppm}$ ) with the following convention for describing multiplicity ( $\mathrm{s}=$ singlet, $\mathrm{d}=$ doublet, $\mathrm{t}=$ triplet, $\mathrm{q}=$ quartet, quint $=$ quintet, $\mathrm{m}=$ multiplet, $\mathrm{br}=$ broad signal, $\mathrm{dd}=$ doublet of doublets, etc). High resolution mass spectroscopy (HRMS) measurements of assayed compounds were recorded using a Waters Acquity UPLC ${ }^{\circledR}$ coupled to a Waters Xevo ${ }^{\circledR}$ QTOF mass spectrometer equipped with a Waters ZSpray ${ }^{\mathrm{TM}}$ electrospray ionization source. 
2.2 Synthesis of $N$-methylmethanamine derivatives ${ }^{13}$

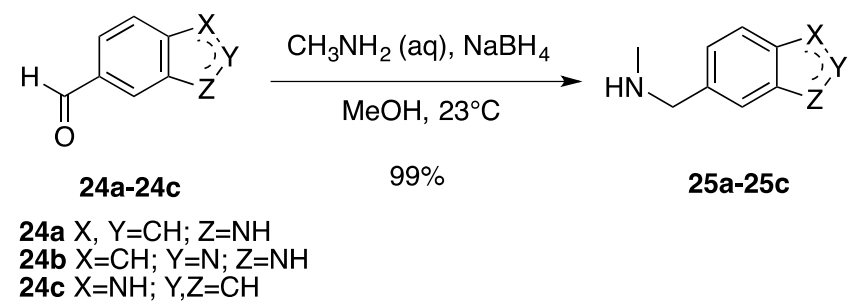

Carbaldehyde derivative $(6.9 \mathrm{mmol})$ was dissolved in anhydrous methanol $(15 \mathrm{~mL})$. Methylamine $(9.9 \mathrm{~mL}$ of $2 \mathrm{M}$ solution in methanol, $19.8 \mathrm{mmol}$ ) was added and the reaction was stirred for $3 \mathrm{hr}$. The solution was concentrated to a yellow oil and then dissolved into anhydrous methanol $(20 \mathrm{~mL})$. Sodium borohydride $(0.26 \mathrm{~g}, 6.9 \mathrm{mmol})$ was added and the mixture was stirred overnight. Water $(11 \mathrm{~mL})$ was added and the solution was concentrated. Sodium hydroxide $(55 \mathrm{~mL}, 1 \mathrm{~N})$ was added and the product was extracted with ethyl acetate $(3 \times 220 \mathrm{~mL})$, dried over $\mathrm{MgSO}_{4}$ and concentrated to afford the title compound.

1-(1H-indol-6-yl)- $N$-methylmethanamine (25a) $(1.092 \mathrm{~g}, 99 \%){ }^{1} \mathrm{H}$ NMR (400 MHz, Methanol- $\left.d_{4}\right) \delta 7.51$ (d, $J=8.1$ $\mathrm{Hz}, 1 \mathrm{H}), 7.35(\mathrm{~s}, 1 \mathrm{H}), 7.21(\mathrm{~d}, J=3.1 \mathrm{~Hz}, 1 \mathrm{H}), 7.00(\mathrm{dd}, J=8.2,1.6 \mathrm{~Hz}, 1 \mathrm{H}), 6.41(\mathrm{~d}, J=3.1 \mathrm{~Hz}, 1 \mathrm{H}), 3.82(\mathrm{~s}, 2 \mathrm{H})$, 2.41 (s, 3H). HRMS (ESI-TOF) calcd for $\mathrm{C}_{10} \mathrm{H}_{13} \mathrm{~N}_{2}[\mathrm{M}+\mathrm{H}]^{+}$161.1079, found 161.1075.

1-(1H-indazol-6-yl)- $\mathrm{N}$-methylmethanamine (25b) (3.461 g, 63\%) ${ }^{1} \mathrm{H}$ NMR (400 MHz, Methanol- $\left.d_{4}\right) \delta 8.02$ (s, $1 \mathrm{H}$ ), $7.75(\mathrm{~d}, J=8.3 \mathrm{~Hz}, 1 \mathrm{H}), 7.51(\mathrm{~s}, 1 \mathrm{H}), 7.16(\mathrm{~d}, J=8.4 \mathrm{~Hz}, 1 \mathrm{H}), 3.88(\mathrm{~s}, 2 \mathrm{H}), 2.43(\mathrm{~s}, 3 \mathrm{H})$. HRMS (ESI-TOF) calcd for $\mathrm{C}_{9} \mathrm{H}_{12} \mathrm{~N}_{3}[\mathrm{M}+\mathrm{H}]^{+}$162.1031, found 162.1040 .

1-(1H-indol-5-yl)- $\mathrm{N}$-methylmethanamine (25c) $(1.100 \mathrm{~g}, 99 \%){ }^{1} \mathrm{H}$ NMR $\left(500 \mathrm{MHz}\right.$, Methanol- $\left.d_{4}\right) \delta 7.51-7.47$ (m, $1 \mathrm{H}), 7.34(\mathrm{~d}, J=8.3 \mathrm{~Hz}, 1 \mathrm{H}), 7.21(\mathrm{~d}, J=3.1 \mathrm{~Hz}, 1 \mathrm{H}), 7.08(\mathrm{dd}, J=8.3,1.6 \mathrm{~Hz}, 1 \mathrm{H}), 6.41(\mathrm{dd}, J=3.1,0.9 \mathrm{~Hz}, 1 \mathrm{H})$, 3.77 (s, 2H), 2.38 (s, 3H). HRMS (ESI-TOF) calcd for $\mathrm{C}_{10} \mathrm{H}_{13} \mathrm{~N}_{2}[\mathrm{M}+\mathrm{H}]^{+}$161.1079, found 161.1083.

2.3 Synthesis of 3-(3-iodophenyl)propanoic acid ${ }^{14}$

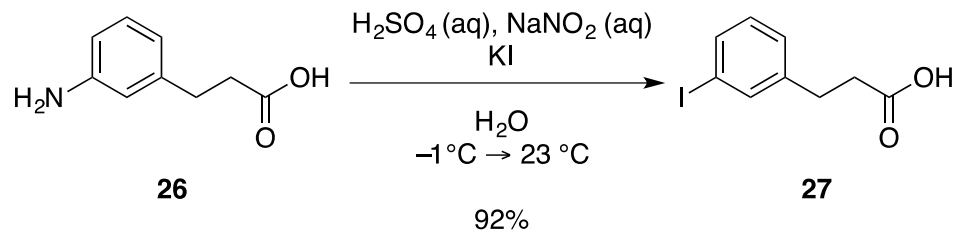

3-(3-iodophenyl)propanoic acid (27) To a stirred solution of (3-aminophenyl)propanoic acid (4.91g, $29.7 \mathrm{mmol})$ in water $(50 \mathrm{~mL})$ and concentrated $\mathrm{H}_{2} \mathrm{SO}_{4}(4 \mathrm{~mL})$ at $-7^{\circ} \mathrm{C}$ (ice-salt bath) was added a solution of $\mathrm{NaNO}_{2}(2.4 \mathrm{~g}, 34.7$ $\mathrm{mmol}$ ) in a minimum amount of water, expelling the nitrite solution below the surface of the solution and keeping the temperature below $0^{\circ} \mathrm{C}$. After 10 minutes, the mixture was checked for the presence of excess $\mathrm{NO}_{2}$ - with starch-KI indicator paper to assure that diazotization was complete. Diethyl ether $(50 \mathrm{~mL})$ was added followed by a solution of 
KI (15 g, $90 \mathrm{mmol}$ ) in a minimum amount of water was added slowly to control the vigorous evolution of $\mathrm{N}_{2}$. After addition was complete, the reaction was stirred and allowed to warm to ambient temperature over 3 hours. The layers were separated, the aqueous layer was extracted with additional diethyl ether $(2 \times 50 \mathrm{~mL})$. The combined ether layers were back extracted with $5 \%$ (w/v) $\mathrm{NaHSO}_{3}(\mathrm{aq})$, brine $\left(1 \mathrm{x} 25 \mathrm{~mL}\right.$ ), dried over $\mathrm{MgSO}_{4}$, filtered, and concentrated to provide the titled compound $(7.55 \mathrm{~g}, 92 \%){ }^{1} \mathrm{H}$ NMR $\left(400 \mathrm{MHz}, \mathrm{DMSO}-d_{6}\right) \delta 12.16(\mathrm{bs}, 1 \mathrm{H}), 7.62(\mathrm{~d}, J=1.7 \mathrm{~Hz}, 1 \mathrm{H})$, 7.57-7.53 (m, 1H), 7.28-7.24 (m, 1H), 7.09 (t, $J=7.7 \mathrm{~Hz}, 1 \mathrm{H}), 2.77$ (t, $J=7.6 \mathrm{~Hz}, 2 \mathrm{H}), 2.52$ (t, $J=7.5 \mathrm{~Hz}, 2 \mathrm{H})$. HRMS (ESI-TOF) calcd for $\mathrm{C}_{9} \mathrm{H}_{10} \mathrm{IO}_{2}[\mathrm{M}+\mathrm{H}]^{+} 276.9725$, found 276.9732 .

2.4 Synthesis of 3-(3-(1H-indol-2-yl)phenyl)propanoic acid. ${ }^{15}$

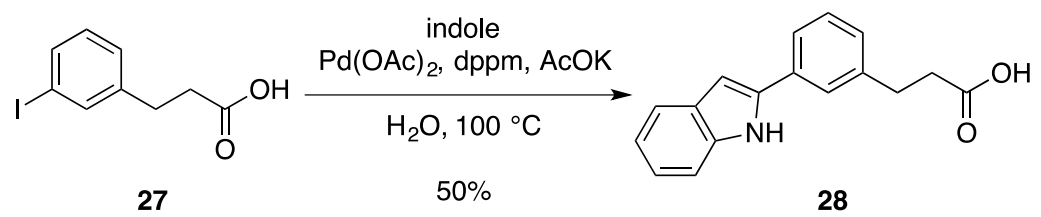

3-(3-(1H-indol-2-yl)phenyl)propanoic acid (28) In a screw-cap vial under air, a mixture of $\mathrm{Pd}(\mathrm{OAc})_{2}(0.53 \mathrm{~g}, 2.34$ mmol, 5 mol \%), dppm (0.9 g, 2.34 mmol, 5 mol\%), AcOK (13.71 g, 139.7 mmol, 3.0 equiv.), iodobenzene (15.45 g, $55.88 \mathrm{mmol}, 1.2$ equiv.), and indole (5.46 g, $46.57 \mathrm{mmol}, 1.0$ equiv.) in degassed $\mathrm{H}_{2} \mathrm{O}(100 \mathrm{~mL})$ was vigorously stirred at $110^{\circ} \mathrm{C}$. After $24 \mathrm{~h}$ the reaction mixture was cooled to room temperature and portioned between $1 \mathrm{~N} \mathrm{HCl}(255 \mathrm{~mL})$ and ethyl acetate $(510 \mathrm{~mL})$. The layers were separated and the aqueous layer was further extracted with $2 \times 510 \mathrm{~mL}$ ethyl acetate. The combined organic layers were dried over $\mathrm{MgSO}_{4}$, filtered and concentrated under reduced pressure. Purification of the residue by flash chromatography $\left(\mathrm{SiO}_{2}\right.$, petroleum ether/EtOAc 9/1) afforded the final compound $(7.42 \mathrm{~g}, 50 \%){ }^{1} \mathrm{H}$ NMR $\left(500 \mathrm{MHz}\right.$, Methanol- $\left.d_{4}\right) \delta 7.70(\mathrm{~s}, 1 \mathrm{H}), 7.66(\mathrm{~d}, J=8.0 \mathrm{~Hz}, 1 \mathrm{H}), 7.54(\mathrm{~d}, J=8.0 \mathrm{~Hz}, 1 \mathrm{H}), 7.41$ (d, $J=8.3 \mathrm{~Hz}, 1 \mathrm{H}), 7.37$ (t, $J=7.7 \mathrm{~Hz}, 1 \mathrm{H}), 7.19$ (d, $J=7.6 \mathrm{~Hz}, 1 \mathrm{H}), 7.11$ (t, $J=7.5 \mathrm{~Hz}, 1 \mathrm{H}), 7.01(\mathrm{t}, J=7.5 \mathrm{~Hz}, 1 \mathrm{H}), 6.81$ (s, 1H), $3.02(\mathrm{t}, J=7.7 \mathrm{~Hz}, 2 \mathrm{H}), 2.70(\mathrm{t}, J=7.7 \mathrm{~Hz}, 2 \mathrm{H})$. HRMS (ESI-TOF) calcd for $\mathrm{C}_{17} \mathrm{H}_{16} \mathrm{NO}_{2}[\mathrm{M}+\mathrm{H}]^{+} 266.1181$, found 266.1176 .

2.5 Synthesis of compounds $29 \mathbf{a}-29 c$

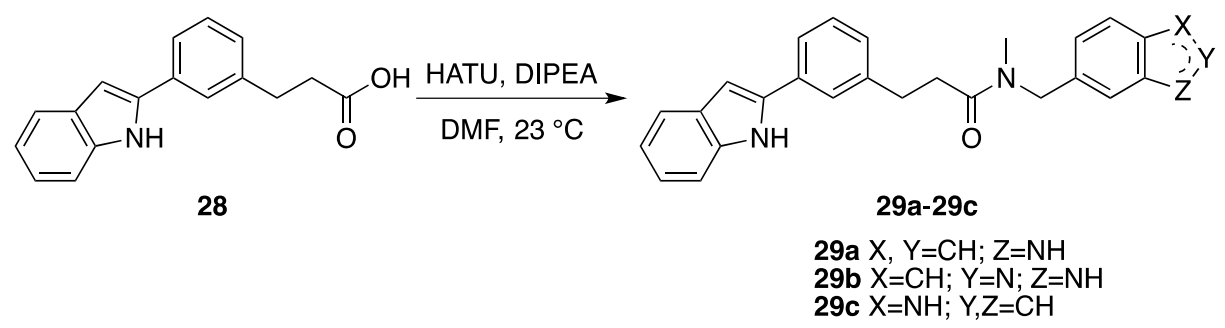

Propanoic acid derivative (3.5mmol, 0.9 equiv.) and HATU (1.49 g, $3.9 \mathrm{mmol}, 1.0$ equiv.) were dissolved in anhydrous DMF (10 mL) for $10 \mathrm{~min}$. at rt. Methylmethanamine derivative $(0.63 \mathrm{~g}, 3.9 \mathrm{mmol}, 1.0$ equiv.) and DIPEA (2.5 mL, 
$14.3 \mathrm{mmol}, 3.65$ equiv.) were added and the reaction mixture was stirred at $\mathrm{rt}$ for $18 \mathrm{~h}$. The reaction mixture was partitioned between ethyl acetate and $0.5 \mathrm{M}$ aqueous $\mathrm{HCl}$. The organic phase was separated and washed sequentially with $0.5 \mathrm{M}$ aqueous $\mathrm{HCl}$, and saturated aqueous $\mathrm{NaCl}$. The organic phase was dried over $\mathrm{MgSO}_{4}$, filtered and concentrated in vacuo. Purification of the residue by flash chromatography $\left(\mathrm{SiO}_{2}\right.$, petroleum ether/EtOAc 9/1) afforded the final compound.

3-(3-(1H-indol-2-yl)phenyl)- $N$-((1H-indol-6-yl)methyl)- $N$-methylpropanamide (29a) $(0.74 \mathrm{~g}, 52 \%){ }^{1} \mathrm{HNMR}(500$ MHz, DMSO- $\left.d_{6}, 80^{\circ} \mathrm{C}\right) \delta 11.16(\mathrm{~s}, 1 \mathrm{H}), 10.70(\mathrm{~s}, 1 \mathrm{H}), 7.83-6.72(\mathrm{~m}, 13 \mathrm{H}), 6.39(\mathrm{~s}, 1 \mathrm{H}), 4.64(\mathrm{~s}, 2 \mathrm{H}), 3.00(\mathrm{t}, J=$ $7.6 \mathrm{~Hz}, 2 \mathrm{H}), 2.92(\mathrm{~s}, 3 \mathrm{H}), 2.79$ (t, $J=7.5 \mathrm{~Hz}, 2 \mathrm{H}) .{ }^{13} \mathrm{C}$ NMR $\left(126 \mathrm{MHz}\right.$, Methanol- $\left.d_{4}, 62^{\circ} \mathrm{C}\right) \delta 173.87,143.53,139.30$, $138.14,134.71$, 131.65, 130.97, 130.50, 129.24, 128.98, 126.60, 126.30, 124.53, 122.14, 121.56, 120.70, 119.29, 110.64, 100.08, 52.22, 35.90, 35.13, 32.38. HRMS (ESI-TOF) calcd for $\mathrm{C}_{27} \mathrm{H}_{26} \mathrm{~N}_{3} \mathrm{O}[\mathrm{M}+\mathrm{H}]^{+} 408.2076$, found 408.2087.

$N$-((1H-indazol-6-yl)methyl)-3-(3-(1H-indol-2-yl)phenyl)- $N$-methylpropanamide (29b) $(0.45 \mathrm{~g}, 77 \%){ }^{1} \mathrm{H}$ NMR $\left(500 \mathrm{MHz}, \mathrm{DMSO}-d_{6}, 80^{\circ} \mathrm{C}\right) \delta 12.75(\mathrm{~s}, 1 \mathrm{H}), 11.22(\mathrm{~s}, 1 \mathrm{H}), 7.99(\mathrm{~s}, 1 \mathrm{H}), 7.81-6.74(\mathrm{~m}, 12 \mathrm{H}), 4.68(\mathrm{~s}, 2 \mathrm{H}), 3.01-$ $2.92(\mathrm{~m}, 5 \mathrm{H}), 2.79(\mathrm{t}, J=7.6 \mathrm{~Hz}, 2 \mathrm{H}) .{ }^{13} \mathrm{C}$ NMR $\left(126 \mathrm{MHz}, \mathrm{DMSO}-d_{6}, 80^{\circ} \mathrm{C}\right) \delta 171.17,141.65,137.51,136.82$, 132.85, 131.95, 128.36, 128.24, 126.93, 124.74, 122.35, 120.95, 119.48, 118.81, 110.78, 98.25, 52.56, 33.79, 33.40, 30.50. HRMS (ESI-TOF) calcd for $\mathrm{C}_{26} \mathrm{H}_{25} \mathrm{~N}_{4} \mathrm{O}[\mathrm{M}+\mathrm{H}]^{+} 409.2028$, found 409.2018.

3-(3-(1H-indol-2-yl)phenyl)- $N$-((1H-indol-5-yl)methyl)- $N$-methylpropanamide (29c) $(0.87 \mathrm{~g}, 61 \%){ }^{1} \mathrm{H}$ NMR (500 MHz, DMSO- $\left.d_{6}, 80^{\circ} \mathrm{C}\right) \delta 11.14(\mathrm{~s}, 1 \mathrm{H}), 10.72(\mathrm{~s}, 1 \mathrm{H}), 7.83-6.71(\mathrm{~m}, 13 \mathrm{H}), 6.38(\mathrm{~s}, 1 \mathrm{H}), 4.62(\mathrm{~s}, 2 \mathrm{H}), 3.01(\mathrm{t}, J=$ $7.5 \mathrm{~Hz}, 2 \mathrm{H}), 2.90(\mathrm{~s}, 3 \mathrm{H}), 2.80(\mathrm{t}, J=7.1 \mathrm{~Hz}, 2 \mathrm{H}) .{ }^{13} \mathrm{C}$ NMR $\left(101 \mathrm{MHz}, \mathrm{DMSO}-d_{6}, 80^{\circ} \mathrm{C}\right) \delta 171.20,141.91,137.68$, 136.99, 135.08, 132.09, 128.54, 128.45, 127.62, 127.17, 125.23, 124.87, 122.50, 121.16, 119.68, 119.03, 110.99, 100.75, 98.44, 50.29, 33.88, 33.12, 30.70. HRMS (ESI-TOF) calcd for $\mathrm{C}_{27} \mathrm{H}_{26} \mathrm{~N}_{3} \mathrm{O}[\mathrm{M}+\mathrm{H}]^{+} 408.2076$, found 408.2065.

2.6 Amidation ${ }^{16,17}$

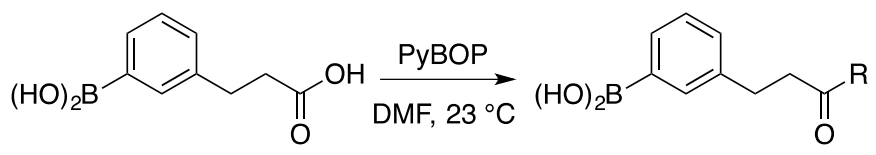

30

31a-31j

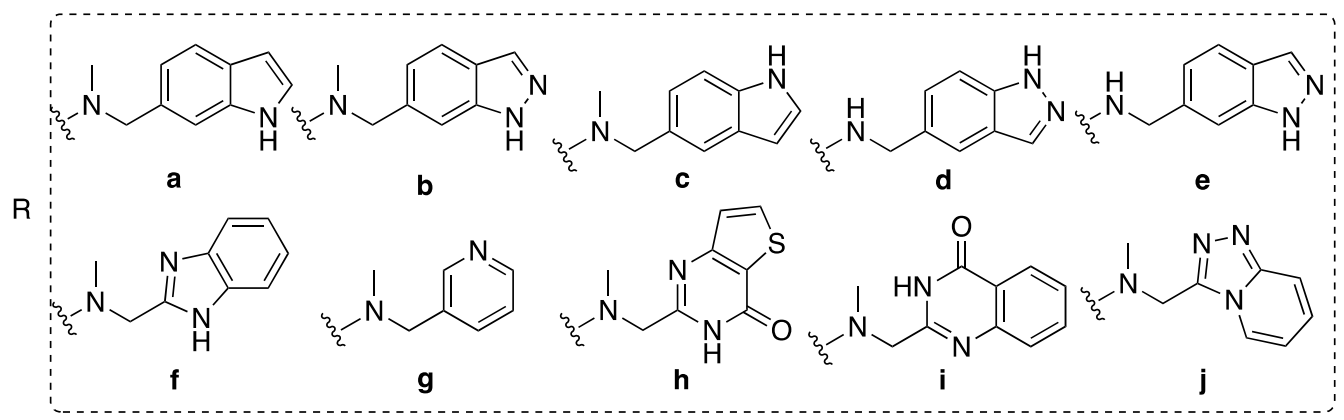


3-(3-boronophenyl)propanoic acid (1.03 mmol, 1.0 equiv.) was introduced into a round bottom flask followed by PyBOP (2.06 mmol, 2.0 equiv.) and $5 \mathrm{ml}$ DMF. The reaction mixture was stirred for $5 \mathrm{~min}$ and the amine derivative ( $2.06 \mathrm{mmol}, 2.0$ equiv.) was added. The reaction was run at room temperature overnight. The reaction mixture was then diluted with $\mathrm{Et}_{2} \mathrm{O}$, and acidified with aqueous saturated $\mathrm{NH}_{4} \mathrm{Cl}$ and $\mathrm{HCl} 1 \mathrm{~N}$ to $\mathrm{pH} 2$. The organic layer was dried over $\mathrm{MgSO}$, filtered and concentrated to provide the titled compound. Purification of the residue by flash chromatography $\left(\mathrm{SiO}_{2}, \mathrm{DCM} / \mathrm{MeOH} 10 \%\right)$ afforded the final compound.

(3-(3-(((1H-indol-6-yl)methyl)(methyl)amino)-3-oxopropyl)phenyl)boronic acid (31a) $(0.241 \mathrm{~g}, 70 \%){ }^{1} \mathrm{H}$ NMR $\left(500 \mathrm{MHz}\right.$, DMSO- $\left.d_{6}, 80^{\circ} \mathrm{C}\right) \delta 10.78(\mathrm{~s}, 1 \mathrm{H}), 7.96(\mathrm{~d}, J=8.4 \mathrm{~Hz}, 1 \mathrm{H}), 7.69(\mathrm{~d}, J=8.4 \mathrm{~Hz}, 1 \mathrm{H}), 7.60(\mathrm{bs}, 1 \mathrm{H}), 7.54(\mathrm{t}$, $J=7.6 \mathrm{~Hz}, 1 \mathrm{H}), 7.48$ (bs, 1H), 7.41 (t, $J=7.7 \mathrm{~Hz}, 1 \mathrm{H}), 7.30-7.17$ (m, 2H), 6.39 (s, 1H), 4.60 (s, 2H), 3.60 (s, 2H), $2.90(\mathrm{~s}, 3 \mathrm{H}), 2.89-2.83(\mathrm{~m}, 2 \mathrm{H}), 2.77-2.72(\mathrm{~m}, 2 \mathrm{H})$. HRMS (ESI-TOF) calcd for $\mathrm{C}_{19} \mathrm{H}_{22} \mathrm{BN}_{2} \mathrm{O}_{3}[\mathrm{M}+\mathrm{H}]^{+} 337.1723$, found 337.1716 .

(3-(3-(((1H-indazol-6-yl)methyl)(methyl)amino)-3-oxopropyl)phenyl)boronic acid (31b) $(0.263 \mathrm{~g}, 74 \%){ }^{1} \mathrm{H}$ NMR $\left(500 \mathrm{MHz}\right.$, DMSO- $\left.d_{6}, 80^{\circ} \mathrm{C}\right) \delta 12.75(\mathrm{~s}, 1 \mathrm{H}), 8.55(\mathrm{~s}, 1 \mathrm{H}), 8.00(\mathrm{~s}, 2 \mathrm{H}), 7.86-7.51(\mathrm{~m}, 2 \mathrm{H}), 7.46-7.10(\mathrm{~m}, 2 \mathrm{H}), 6.95$ (d, $J=8.6 \mathrm{~Hz}, 1 \mathrm{H}), 4.65$ (s, 2H), 3.64 (s, 2H), $4.82-4.54$ (m, 5H), $2.76-2.63$ (m, 2H).HRMS (ESI-TOF) calcd for $\mathrm{C}_{18} \mathrm{H}_{21} \mathrm{BN}_{3} \mathrm{O}_{3}[\mathrm{M}+\mathrm{H}]^{+}$338.1676, found 338.1680.

(3-(3-(((1H-indol-5-yl)methyl)(methyl)amino)-3-oxopropyl)phenyl)boronic acid (31c) $(0.340 \mathrm{~g}, 83 \%){ }^{1} \mathrm{H}$ NMR $\left(500 \mathrm{MHz}\right.$, DMSO- $\left.d_{6}, 80^{\circ} \mathrm{C}\right) \delta 10.80(\mathrm{~s}, 1 \mathrm{H}), 7.68(\mathrm{~s}, 1 \mathrm{H}), 7.63-7.54(\mathrm{~m}, 1 \mathrm{H}), 7.40-7.31(\mathrm{~m}, 2 \mathrm{H}), 7.31-7.17(\mathrm{~m}$, $3 \mathrm{H}), 6.97-6.89(\mathrm{~m}, 1 \mathrm{H}), 6.38(\mathrm{~s}, 1 \mathrm{H}), 4.58(\mathrm{~s}, 2 \mathrm{H}), 3.60(\mathrm{~s}, 2 \mathrm{H}), 2.97-2.87(\mathrm{~m}, 2 \mathrm{H}), 2.86(\mathrm{~s}, 3 \mathrm{H}), 2.77$ - $2.64(\mathrm{~m}$, 2H). HRMS (ESI-TOF) calcd for $\mathrm{C}_{19} \mathrm{H}_{22} \mathrm{BN}_{2} \mathrm{O}_{3}[\mathrm{M}+\mathrm{H}]^{+} 337.1723$, found 337.1708.

(3-(3-(((1H-indazol-5-yl)methyl)amino)-3-oxopropyl)phenyl)boronic acid (31d) $(0.115 \mathrm{~g}, 62 \%){ }^{1} \mathrm{H}$ NMR (500 MHz, DMSO- $\left.d_{6}, 80^{\circ} \mathrm{C}\right) \delta 12.70(\mathrm{~s}, 1 \mathrm{H}), 8.14(\mathrm{~s}, 1 \mathrm{H}), 7.98(\mathrm{~s}, 1 \mathrm{H}), 7.71-7.62(\mathrm{~m}, 2 \mathrm{H}), 7.58(\mathrm{~d}, J=6.7 \mathrm{~Hz}, 1 \mathrm{H}), 7.36$ (s, 1H), $7.26-7.18(\mathrm{~m}, 2 \mathrm{H}), 6.96(\mathrm{~d}, J=8.3 \mathrm{~Hz}, 1 \mathrm{H}), 4.38(\mathrm{~d}, J=5.9 \mathrm{~Hz}, 2 \mathrm{H}), 3.94(\mathrm{~s}, 2 \mathrm{H}), 2.87(\mathrm{t}, J=7.8 \mathrm{~Hz}, 2 \mathrm{H})$, $2.54-2.45$ (m, 2H). HRMS (ESI-TOF) calcd for $\mathrm{C}_{17} \mathrm{H}_{19} \mathrm{BN}_{3} \mathrm{O}_{3}[\mathrm{M}+\mathrm{H}]^{+} 324.1518$, found 324.1513.

(3-(3-(((1H-indazol-6-yl)methyl)amino)-3-oxopropyl)phenyl)boronic acid (31e) $(0.121 \mathrm{~g}, 62 \%){ }^{1} \mathrm{H}$ NMR (500 MHz, Methanol- $\left.d_{4}\right) \delta 7.96(\mathrm{~s}, 1 \mathrm{H}), 7.65-7.57(\mathrm{~m}, 1 \mathrm{H}), 7.52-7.44(\mathrm{~m}, 2 \mathrm{H}), 7.43(\mathrm{~d}, J=8.6 \mathrm{~Hz}, 1 \mathrm{H}), 7.27-7.21(\mathrm{~m}$, $2 \mathrm{H}), 7.16(\mathrm{~d}, J=8.5 \mathrm{~Hz}, 1 \mathrm{H}), 4.40(\mathrm{~s}, 2 \mathrm{H}), 3.35(\mathrm{~s}, 2 \mathrm{H}), 2.95$ (t, $J=7.4 \mathrm{~Hz}, 2 \mathrm{H}), 2.56$ (t, $J=7.5 \mathrm{~Hz}, 2 \mathrm{H})$. HRMS (ESITOF) calcd for $\mathrm{C}_{17} \mathrm{H}_{19} \mathrm{BN}_{3} \mathrm{O}_{3}[\mathrm{M}+\mathrm{H}]^{+} 324.1519$, found 324.1513 .

(3-(3-)((1H-benzo[d] imidazol-2-yl)methyl)(methyl)amino)-3-oxopropyl)phenyl)boronic acid (31f) $(0.027 \mathrm{~g}, 15 \%)$ ${ }^{1} \mathrm{H}$ NMR $\left(500 \mathrm{MHz}\right.$, DMSO- $\left.d_{6}, 80^{\circ} \mathrm{C}\right) \delta 7.70(\mathrm{~s}, 2 \mathrm{H}), 7.63(\mathrm{~s}, 1 \mathrm{H}), 7.55(\mathrm{~d}, J=7.4 \mathrm{~Hz}, 1 \mathrm{H}), 7.50(\mathrm{~s}, 2 \mathrm{H}), 7.29-7.16$ (m, 2H), $7.18-7.12(\mathrm{~m}, 1 \mathrm{H}), 4.70(\mathrm{~s}, 2 \mathrm{H}), 3.18-2.98(\mathrm{~m}, 5 \mathrm{H}), 2.90-2.83(\mathrm{~m}, 2 \mathrm{H}), 2.74-2.68$ (m, 2H). HRMS (ESI-TOF) calcd for $\mathrm{C}_{18} \mathrm{H}_{21} \mathrm{BN}_{3} \mathrm{O}_{3}[\mathrm{M}+\mathrm{H}]^{+} 338.1676$, found 338.1679. 
(3-(3-(methyl(pyridin-3-ylmethyl)amino)-3-oxopropyl)phenyl)boronic acid (31g) $(0.100 \mathrm{~g}, 59 \%){ }^{1} \mathrm{H}$ NMR (500 MHz, DMSO- $\left.d_{6}, 80^{\circ} \mathrm{C}\right) \delta 8.43(\mathrm{~d}, J=4.7 \mathrm{~Hz}, 1 \mathrm{H}), 8.40(\mathrm{~d}, J=2.3 \mathrm{~Hz}, 1 \mathrm{H}), 7.69(\mathrm{~s}, 1 \mathrm{H}), 7.63(\mathrm{~s}, 1 \mathrm{H}), 7.57(\mathrm{~d}, J=7.0$ $\mathrm{Hz}, 1 \mathrm{H}), 7.52(\mathrm{~d}, J=7.8 \mathrm{~Hz}, 1 \mathrm{H}), 7.34-7.26(\mathrm{~m}, 1 \mathrm{H}), 7.26-7.17(\mathrm{~m}, 1 \mathrm{H}), 4.52(\mathrm{~s}, 2 \mathrm{H}), 3.30(\mathrm{~s}, 2 \mathrm{H}), 2.92-2.82(\mathrm{~m}$, $5 \mathrm{H}), 2.67(\mathrm{t}, J=7.6 \mathrm{~Hz}, 2 \mathrm{H})$. HRMS (ESI-TOF) calcd for $\mathrm{C}_{16} \mathrm{H}_{20} \mathrm{BN}_{2} \mathrm{O}_{3}[\mathrm{M}+\mathrm{H}]^{+} 299.1567$, found 299.1571 .

(3-(3-(methyl((4-oxo-3,4-dihydrothieno[3,2- $d$ ]pyrimidin-2-yl)methyl)amino)-3-oxopropyl)phenyl)boronic acid (31h) $(0.137 \mathrm{~g}, 64 \%){ }^{1} \mathrm{H}$ NMR $\left(500 \mathrm{MHz}, \mathrm{DMSO}-d_{6}, 80^{\circ} \mathrm{C}\right) \delta 12.01(\mathrm{~s}, 1 \mathrm{H}), 8.07(\mathrm{~d}, J=5.2 \mathrm{~Hz}, 1 \mathrm{H}), 7.71-7.60(\mathrm{~m}$, 2H), 7.57 (d, $J=7.1 \mathrm{~Hz}, 1 \mathrm{H}), 7.30$ (d, $J=5.2 \mathrm{~Hz}, 1 \mathrm{H}), 7.28-7.16(\mathrm{~m}, 1 \mathrm{H}), 4.49$ (s, 2H), 3.19 (s, 2H), 3.09 (s, 3H), $2.89-2.82(\mathrm{~m}, 2 \mathrm{H}), 2.75-2.63(\mathrm{~m}, 2 \mathrm{H})$. HRMS (ESI-TOF) calcd for $\mathrm{C}_{17} \mathrm{H}_{19} \mathrm{BN}_{3} \mathrm{O}_{4} \mathrm{~S}[\mathrm{M}+\mathrm{H}]^{+} 372.1189$, found 372.1194 .

(3-(3-oxo-3-(((4-oxo-3,4-dihydroquinazolin-2-yl)methyl)amino)propyl)phenyl)boronic acid (31i) (0.156g, 72\%) ${ }^{1} \mathrm{H}$ NMR $\left(500 \mathrm{MHz}\right.$, DMSO- $\left.d_{6}, 80^{\circ} \mathrm{C}\right) \delta 11.79(\mathrm{~s}, 1 \mathrm{H}), 8.10(\mathrm{~d}, J=7.8 \mathrm{~Hz}, 1 \mathrm{H}), 7.77(\mathrm{t}, J=7.7 \mathrm{~Hz}, 1 \mathrm{H}), 7.65(\mathrm{~s}, 2 \mathrm{H})$, $7.58(\mathrm{~d}, J=8.2 \mathrm{~Hz}, 1 \mathrm{H}), 7.47(\mathrm{t}, J=7.5 \mathrm{~Hz}, 1 \mathrm{H}), 7.33-7.14(\mathrm{~m}, 2 \mathrm{H}), 4.47(\mathrm{~s}, 2 \mathrm{H}), 3.22(\mathrm{~s}, 2 \mathrm{H}), 3.12(\mathrm{~s}, 3 \mathrm{H}), 2.87$ (t, $J=7.8 \mathrm{~Hz}, 2 \mathrm{H}$ ), 2.72 (t, $J=7.7 \mathrm{~Hz}, 2 \mathrm{H}$ ). HRMS (ESI-TOF) calcd for $\mathrm{C}_{19} \mathrm{H}_{21} \mathrm{BN}_{3} \mathrm{O}_{4}[\mathrm{M}+\mathrm{H}]^{+} 366.1625$, found 366.1620 .

(3-(3-(([1,2,4]triazolo[4,3-a]pyridin-3-ylmethyl)(methyl)amino)-3-oxopropyl)phenyl)boronic acid (31j) (0.124g, $64 \%){ }^{1} \mathrm{H}$ NMR (500 MHz, DMSO- $\left.d_{6}\right) \delta 8.35(\mathrm{~s}, 1 \mathrm{H}), 7.73-7.66(\mathrm{~m}, 1 \mathrm{H}), 7.61(\mathrm{~s}, 1 \mathrm{H}), 7.54(\mathrm{~d}, J=7.1 \mathrm{~Hz}, 1 \mathrm{H}), 7.37$ $(\mathrm{dd}, J=9.3,6.5 \mathrm{~Hz}, 1 \mathrm{H}), 7.19(\mathrm{~s}, 1 \mathrm{H}), 7.15(\mathrm{t}, J=7.4 \mathrm{~Hz}, 1 \mathrm{H}), 6.94(\mathrm{t}, J=6.8 \mathrm{~Hz}, 1 \mathrm{H}), 5.01(\mathrm{~s}, 2 \mathrm{H}), 4.49$ (s, 2H), $2.94(\mathrm{~s}, 3 \mathrm{H}), 2.85(\mathrm{t}, J=7.5 \mathrm{~Hz}, 2 \mathrm{H}), 2.67(\mathrm{t}, J=7.5 \mathrm{~Hz}, 2 \mathrm{H})$. HRMS (ESI-TOF) calcd for $\mathrm{C}_{17} \mathrm{H}_{20} \mathrm{BN}_{4} \mathrm{O}_{3}[\mathrm{M}+\mathrm{H}]^{+}$ 339.1628 , found 339.1632 .

2.7 Synthesis of compounds 32a-32d and $\mathbf{3 3 a} \mathbf{a}-\mathbf{3 3} \mathbf{j}^{18}$
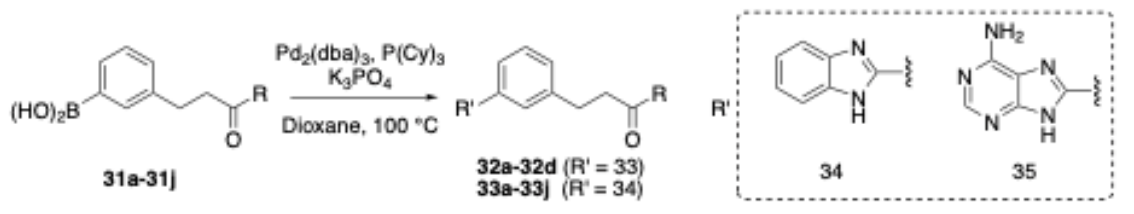

In the air, the boronic acid derivatives (1.10mmol), $\mathrm{Pd}_{2}(\mathrm{dba})_{3}(9.2 \mathrm{mg}, 0.010 \mathrm{mmol})$, and $\mathrm{P}(\mathrm{Cy})_{3}(6.7 \mathrm{mg}, 0.024 \mathrm{mmol})$ are added to a $25 \mathrm{~mL}$ Schlenk flask equipped with a stir bar. The flask is evacuated and refilled with argon five times. Dioxane $(3.0 \mathrm{~mL})$, the halide derivatives $(1.00 \mathrm{mmol}$; if the halide is a solid, then it is added prior to the evacuationrefill cycle), and aqueous $\mathrm{K}_{3} \mathrm{PO}_{4}(1.27 \mathrm{M}, 1.33 \mathrm{~mL}, 1.70 \mathrm{mmol})$ are added by syringe. The Schlenk flask is sealed and heated in an oil bath at $100{ }^{\circ} \mathrm{C}$ for 18 hours with vigorous stirring. The mixture is then filtered through a pad of silica 
gel (EtOAc washings). Next, the filtrate is concentrated under reduced pressure, and the aqueous residue is extracted three times with EtOAc. The combined extracts are dried over anhydrous $\mathrm{MgSO}_{4}$, filtered and concentrated. The residue is then purified by column chromatography on silica gel with DCM/MeOH (1-15\%).

The aqueous solution of $\mathrm{K}_{3} \mathrm{PO}_{4}$ was prepared by adding de-ionized water $(3.0 \mathrm{~mL})$ to $\mathrm{K}_{3} \mathrm{PO}_{4}(0.84 \mathrm{~g}, 3.84 \mathrm{mmol})$ in a $20 \mathrm{~mL}$ vial. In order to facilitate the dissolution of the $\mathrm{K}_{3} \mathrm{PO}_{4}$, the mixture was sonicated for $1 \mathrm{~min}$

3-(3-(1H-benzo[d]imidazol-2-yl)phenyl)- $N$-((1H-indol-6-yl)methyl)- $N$-methylpropanamide (32a) $(0.090 \mathrm{~g}, 23 \%)$ ${ }^{1} \mathrm{H}$ NMR $\left(500 \mathrm{MHz}\right.$, DMSO- $\left.d_{6}, 80^{\circ} \mathrm{C}\right) \delta 12.04(\mathrm{~s}, 1 \mathrm{H}), 10.76(\mathrm{~s}, 1 \mathrm{H}), 7.58-6.79(\mathrm{~m}, 9 \mathrm{H}), 6.79-6.35(\mathrm{~m}, 4 \mathrm{H}), 4.60$ $(\mathrm{s}, 2 \mathrm{H}), 2.88(\mathrm{~s}, 3 \mathrm{H}), 2.82(\mathrm{t}, J=7.5 \mathrm{~Hz}, 2 \mathrm{H}), 2.66(\mathrm{t}, J=7.6 \mathrm{~Hz}, 2 \mathrm{H}) .{ }^{13} \mathrm{C}$ NMR $\left(126 \mathrm{MHz}\right.$, DMSO- $\left.d_{6}, 80^{\circ} \mathrm{C}\right) 170.99$, 156.89, 142.43, 140.26, 135.81, 135.31, 132.11, 128.84, 128.57, 127.92, 127.66, 124.74, 122.12, 119.69, 118.47, $114.95,112.52,100.50,59.70,33.71,30.62,30.44$. HRMS (ESI-TOF) calcd for $\mathrm{C}_{26} \mathrm{H}_{25} \mathrm{~N}_{4} \mathrm{O}[\mathrm{M}+\mathrm{H}]^{+} 409.2028$, found 409.2034 .

3-(3-(1H-benzo[d] imidazol-2-yl)phenyl)- $N$-((1H-indazol-6-yl)methyl)- $N$-methylpropanamide $\quad(32 b) \quad(0.110 \mathrm{~g}$, 28\%) ${ }^{1} \mathrm{H}$ NMR (500 MHz, DMSO- $\left.d_{6}, 80^{\circ} \mathrm{C}\right) 12.72(\mathrm{ss}, 2 \mathrm{H}), 8.28(\mathrm{~s}, 1 \mathrm{H}), 8.00(\mathrm{~s}, 1 \mathrm{H}), 7.96(\mathrm{~s}, 1 \mathrm{H}), 7.86-7.50(\mathrm{~m}$, 3H), 7.35 (bs, 1H), $7.31-7.07$ (m, 3H), $7.02-6.84(\mathrm{~m}, 2 \mathrm{H}), 4.61$ (s, 2H), $2.98-2.82(\mathrm{~m}, 5 \mathrm{H}), 2.77-2.67$ (m, 2H). ${ }^{13} \mathrm{C}$ NMR $\left(126 \mathrm{MHz}\right.$, DMSO- $\left.d_{6}, 80^{\circ} \mathrm{C}\right) \delta 171.23,152.35,141.04,140.01,139.67,137.00,135.49,133.57,132.80$, $131.15,129.39,126.73,121.57,120.06,120.00,114.81,108.30,50.08,33.83,31.15,30.52$. HRMS (ESI-TOF) calcd for $\mathrm{C}_{25} \mathrm{H}_{24} \mathrm{~N}_{5} \mathrm{O}[\mathrm{M}+\mathrm{H}]^{+} 410.1981$, found 410.1965 .

3-(3-(1H-benzo[d] imidazol-2-yl)phenyl)- $\boldsymbol{N}$-((1H-indol-5-yl)methyl)- $\boldsymbol{N}$-methylpropanamide (32c) $(0.071 \mathrm{~g}, 17 \%)$ ${ }^{1} \mathrm{H}$ NMR $\left(500 \mathrm{MHz}\right.$, DMSO- $\left.d_{6}, 80^{\circ} \mathrm{C}\right) \delta 12.95(\mathrm{~s}, 1 \mathrm{H}), 10.81(\mathrm{~s}, 1 \mathrm{H}), 8.15-7.10(\mathrm{~m}, 9 \mathrm{H}), 7.10-6.11(\mathrm{~m}, 4 \mathrm{H}), 4.58$ (s, 2H), $2.97-2.78(\mathrm{~m}, 5 \mathrm{H}), 2.78-2.62(\mathrm{~m}, 2 \mathrm{H}) .{ }^{13} \mathrm{C}$ NMR (126 MHz, DMSO- $\left.d_{6}, 80^{\circ} \mathrm{C}\right) 170.95,156.90,139.77$, 134.92, 133.60, 131.14, 130.71, 128.54, 127.46, 126.71, 125.01, 118.48, 114.97, 112.50, 110.95, 100.57, 50.06, 33.95, 33.71, 30.58. HRMS (ESI-TOF) calcd for $\mathrm{C}_{26} \mathrm{H}_{25} \mathrm{~N}_{4} \mathrm{O}[\mathrm{M}+\mathrm{H}]^{+} 409.2028$, found 409.2038.

3-(3-(1H-benzo[d]imidazol-2-yl)phenyl)- $N$-((1H-indazol-6-yl)methyl)propanamide (32d) $(0.103 \mathrm{~g}, 26 \%){ }^{1} \mathrm{H}$ NMR (500 MHz, Methanol- $\left.d_{4}\right) \delta 8.65-7.63(\mathrm{~m}, 4 \mathrm{H}), 7.54-6.95(\mathrm{~m}, 5 \mathrm{H}), 6.76-6.53(\mathrm{~m}, 3 \mathrm{H}), 4.44(\mathrm{~s}, 1 \mathrm{H}), 4.43$ $(\mathrm{s}, 1 \mathrm{H}), 2.88(\mathrm{t}, J=7.5 \mathrm{~Hz}, 2 \mathrm{H}), 2.53(\mathrm{t}, J=7.5 \mathrm{~Hz}, 2 \mathrm{H}) .{ }^{13} \mathrm{C}$ NMR $\left(126 \mathrm{MHz}\right.$, Methanol- $\left.d_{4}\right) \delta 175.12,158.55$, 143.58, 138.69, 136.82, 134.82, 132.45, 130.46, 128.18, 125.21, 122.97, 120.68, 120.13, 116.40, 114.15, 111.18, 44.23, 38.91, 32.90. HRMS (ESI-TOF) calcd for $\mathrm{C}_{24} \mathrm{H}_{22} \mathrm{~N}_{5} \mathrm{O}[\mathrm{M}+\mathrm{H}]^{+} 396.1824$, found 396.1819 .

$\boldsymbol{N}$-((1H-indol-6-yl)methyl)-3-(3-(6-amino-9H-purin-8-yl)phenyl)- $\boldsymbol{N}$-methylpropanamide (33a) $(0.171 \mathrm{~g}, 39 \%){ }^{1} \mathrm{H}$ NMR $\left(500 \mathrm{MHz}\right.$, DMSO- $\left.d_{6}, 80^{\circ} \mathrm{C}\right) \delta 10.79(\mathrm{~s}, 1 \mathrm{H}), 8.94(\mathrm{~s}, 1 \mathrm{H}), 7.48(\mathrm{~d}, J=8.1 \mathrm{~Hz}, 2 \mathrm{H}), 7.32-7.16(\mathrm{~m}, 3 \mathrm{H}), 7.04$ $(\mathrm{t}, J=7.5 \mathrm{~Hz}, 2 \mathrm{H}), 6.85(\mathrm{~s}, 1 \mathrm{H}), 6.73-6.53(\mathrm{~m}, 3 \mathrm{H}), 6.39(\mathrm{~s}, 1 \mathrm{H}), 4.60(\mathrm{~s}, 2 \mathrm{H}), 2.87(\mathrm{~s}, 3 \mathrm{H}), 2.85-2.76(\mathrm{~m}, 2 \mathrm{H})$, $2.65(\mathrm{t}, J=7.6 \mathrm{~Hz}, 2 \mathrm{H}) .{ }^{13} \mathrm{C}$ NMR $\left(126 \mathrm{MHz}, \mathrm{DMSO}-d_{6}, 80^{\circ} \mathrm{C}\right) \delta 171.04,156.92,142.47,140.82,135.82,134.93$, 
$130.13,128.63,126.56,124.80,119.49,118.74,118.51,114.98,112.54,110.28,103.25,100.53,50.14,33.85,33.67$, 30.47. HRMS (ESI-TOF) calcd for $\mathrm{C}_{24} \mathrm{H}_{24} \mathrm{~N}_{7} \mathrm{O}[\mathrm{M}+\mathrm{H}]^{+} 426.2042$, found 426.2036.

$N$-((1H-indazol-6-yl)methyl)-3-(3-(6-amino-9H-purin-8-yl)phenyl)- $N$-methylpropanamide (33b) (0.122 g, 29\%). ${ }^{1} \mathrm{H}$ NMR $\left(500 \mathrm{MHz}, \mathrm{DMSO}-d_{6}, 80^{\circ} \mathrm{C}\right) \delta 12.74(\mathrm{~s}, 1 \mathrm{H}), 8.92(\mathrm{~s}, 1 \mathrm{H}), 8.00(\mathrm{~s}, 1 \mathrm{H}), 7.69(\mathrm{~d}, J=8.2 \mathrm{~Hz}, 1 \mathrm{H}), 7.35(\mathrm{~s}$, 1H), $7.04(\mathrm{t}, J=7.4 \mathrm{~Hz}, 1 \mathrm{H}), 6.99-6.87(\mathrm{~m}, 2 \mathrm{H}), 6.73-6.54(\mathrm{~m}, 5 \mathrm{H}), 4.65(\mathrm{~s}, 2 \mathrm{H}), 2.90(\mathrm{~s}, 3 \mathrm{H}), 2.85-2.77(\mathrm{~m}, 2 \mathrm{H})$, $2.66(\mathrm{t}, J=7.7 \mathrm{~Hz}, 2 \mathrm{H}) .{ }^{13} \mathrm{C}$ NMR $\left(126 \mathrm{MHz}, \mathrm{DMSO}-d_{6}, 80^{\circ} \mathrm{C}\right) \delta 170.78,158.37,156.91,142.30,132.65,131.07$, $128.55,125.69,122.50,118.41,117.98,114.90,112.51,111.39,109.48,55.27,41.95,36.53$, 30.69. HRMS (ESITOF) calcd for $\mathrm{C}_{23} \mathrm{H}_{23} \mathrm{~N}_{8} \mathrm{O}[\mathrm{M}+\mathrm{H}]^{+} 427.1995$, found 427.1987 .

$\boldsymbol{N}$-((1H-indol-5-yl)methyl)-3-(3-(6-amino-9H-purin-8-yl)phenyl)- $\boldsymbol{N}$-methylpropanamide $(33 \mathrm{c})(0.125 \mathrm{~g}, 28 \%){ }^{1} \mathrm{H}$ NMR (400 MHz, DMSO- $\left.d_{6}, 80^{\circ} \mathrm{C}\right) \delta 10.80(\mathrm{~s}, 1 \mathrm{H}), 8.90(\mathrm{~s}, 1 \mathrm{H}), 7.68(\mathrm{~s}, 1 \mathrm{H}), 7.63-7.54(\mathrm{~m}, 2 \mathrm{H}), 7.38-7.31(\mathrm{~m}$, 2H), $7.30-7.18(\mathrm{~m}, 2 \mathrm{H}), 7.04(\mathrm{t}, J=7.6 \mathrm{~Hz}, 1 \mathrm{H}), 6.93(\mathrm{~d}, J=8.4 \mathrm{~Hz}, 1 \mathrm{H}), 6.66(\mathrm{~s}, 1 \mathrm{H}), 6.59(\mathrm{~d}, J=8.1 \mathrm{~Hz}, 1 \mathrm{H}), 6.39$ $(\mathrm{s}, 1 \mathrm{H}), 4.58(\mathrm{~s}, 2 \mathrm{H}), 3.04(\mathrm{~s}, 3 \mathrm{H}), 2.92-2.79(\mathrm{~m}, 2 \mathrm{H}), 2.74-2.63(\mathrm{~m}, 2 \mathrm{H}) .{ }^{13} \mathrm{C} \mathrm{NMR}\left(126 \mathrm{MHz}, \mathrm{DMSO}-d_{6}, 80^{\circ} \mathrm{C}\right)$ $\delta 170.94,156.91,142.48,139.78,134.92,133.62,131.15,129.44,128.56,126.72,125.00,118.49,114.98,112.50$, 110.97, 100.57, 59.18, 33.78, 30.57, 30.43. HRMS (ESI-TOF) calcd for $\mathrm{C}_{24} \mathrm{H}_{24} \mathrm{~N}_{7} \mathrm{O}[\mathrm{M}+\mathrm{H}]^{+} 426.2042$, found 426.2024 .

N-((1H-indazol-6-yl)methyl)-3-(3-(6-amino-9H-purin-8-yl)phenyl)propanamide (33d) $(0.125$ g, $30 \%){ }^{1} \mathrm{H}$ NMR $\left(500 \mathrm{MHz}\right.$, Methanol- $\left.d_{4}\right) \delta 8.38(\mathrm{~s}, 1 \mathrm{H}), 7.98(\mathrm{~s}, 1 \mathrm{H}), 7.50-7.41(\mathrm{~m}, 2 \mathrm{H}), 7.20(\mathrm{dd}, J=8.6,1.6 \mathrm{~Hz}, 1 \mathrm{H}), 7.05(\mathrm{t}, J=$ $8.1 \mathrm{~Hz}, 1 \mathrm{H}), 6.71-6.60(\mathrm{~m}, 3 \mathrm{H}), 4.43(\mathrm{~s}, 1 \mathrm{H}), 4.42(\mathrm{~s}, 1 \mathrm{H}), 2.88(\mathrm{t}, J=7.5 \mathrm{~Hz}, 2 \mathrm{H}), 2.53(\mathrm{t}, J=7.5 \mathrm{~Hz}, 2 \mathrm{H}) .{ }^{13} \mathrm{C}$ NMR (126 MHz, Methanol- $\left.d_{4}\right) \delta 175.12,158.54,143.58,141.01,134.73,132.42,130.46,128.18,125.52,124.30$, 120.68, 120.11, 116.40, 114.15, 111.23, 44.10, 38.85, 32.88. HRMS (ESI-TOF) calcd for $\mathrm{C}_{22} \mathrm{H}_{21} \mathrm{~N}_{8} \mathrm{O}[\mathrm{M}+\mathrm{H}]^{+}$ 413.1838, found 413.1843 .

$\boldsymbol{N}$-((1H-indazol-6-yl)methyl)-3-(3-(6-amino-9H-purin-8-yl)phenyl)propanamide (33e) $(0.018 \mathrm{~g}, 72 \%){ }^{1} \mathrm{H} \mathrm{NMR}$ $\left(500 \mathrm{MHz}, \mathrm{DMSO}-d_{6}, 80^{\circ} \mathrm{C}\right) \delta 13.83(\mathrm{~s}, 1 \mathrm{H}), 12.71(\mathrm{~s}, 1 \mathrm{H}), 8.18(\mathrm{~s}, 1 \mathrm{H}), 8.13(\mathrm{~s}, 1 \mathrm{H}), 7.97(\mathrm{~s}, 1 \mathrm{H}), 7.94(\mathrm{~s}, 1 \mathrm{H}), 7.90$ $(\mathrm{d}, J=7.8 \mathrm{~Hz}, 1 \mathrm{H}), 7.59(\mathrm{~d}, J=8.3 \mathrm{~Hz}, 1 \mathrm{H}), 7.41(\mathrm{t}, J=7.7 \mathrm{~Hz}, 1 \mathrm{H}), 7.34(\mathrm{~s}, 2 \mathrm{H}), 6.92(\mathrm{~d}, J=8.3 \mathrm{~Hz}, 1 \mathrm{H}), 6.74(\mathrm{~s}$, $2 \mathrm{H}), 4.37(\mathrm{~d}, J=5.9 \mathrm{~Hz}, 2 \mathrm{H}), 2.97(\mathrm{t}, J=7.6 \mathrm{~Hz}, 2 \mathrm{H}), 2.56(\mathrm{t}, J=7.7 \mathrm{~Hz}, 2 \mathrm{H}) .{ }^{13} \mathrm{C} \mathrm{NMR}\left(126 \mathrm{MHz}, \mathrm{DMSO}-d_{6}, 80^{\circ} \mathrm{C}\right)$ $\delta 171.87,152.48,146.27,142.12,140.43,137.69,133.33,130.24,129.61,129.03,126.47,124.25,123.92,121.99$, 120.54, 120.39, 108.39, 42.74, 36.90, 31.16. HRMS (ESI-TOF) calcd for $\mathrm{C}_{22} \mathrm{H}_{21} \mathrm{~N}_{8} \mathrm{O}[\mathrm{M}+\mathrm{H}]^{+} 413.1838$, found 413.1868 .

N-((1H-benzo[d]imidazol-2-yl)methyl)-3-(3-(6-amino-9H-purin-8-yl)phenyl)- $N$-methylpropanamide $(0.026 \mathrm{~g}, 92 \%){ }^{1} \mathrm{H}$ NMR $\left(500 \mathrm{MHz}, \mathrm{DMSO}_{6}, 80^{\circ} \mathrm{C}\right) \delta 13.07$ (s, 1H), $12.18(\mathrm{~s}, 1 \mathrm{H}), 8.14(\mathrm{~s}, 1 \mathrm{H}), 8.05(\mathrm{~s}, 1 \mathrm{H}), 8.00-$ $7.90(\mathrm{~m}, 1 \mathrm{H}), 7.50(\mathrm{~s}, 2 \mathrm{H}), 7.45-7.34(\mathrm{~m}, 2 \mathrm{H}), 7.19-7.10(\mathrm{~m}, 2 \mathrm{H}), 6.78(\mathrm{~s}, 2 \mathrm{H}), 4.75(\mathrm{~s}, 2 \mathrm{H}), 3.11(\mathrm{~s}, 3 \mathrm{H}), 3.03-$ $2.96(\mathrm{~m}, 2 \mathrm{H}), 2.88-2.79(\mathrm{~m}, 2 \mathrm{H}) .{ }^{13} \mathrm{C} \mathrm{NMR}\left(126 \mathrm{MHz}, \mathrm{DMSO}-d_{6}, 80^{\circ} \mathrm{C}\right) \delta 171.46,155.70,155.05,152.03,149.32$, 
$145.35,141.88,138.47,129.53,128.41,126.11,123.67,121.16,121.01,114.87,49.36,33.64,30.25,20.49$. HRMS (ESI-TOF) calcd for $\mathrm{C}_{23} \mathrm{H}_{23} \mathrm{~N}_{8} \mathrm{O}[\mathrm{M}+\mathrm{H}]^{+}$427.1995, found 427.1976.

3-(3-(6-amino-9H-purin-8-yl)phenyl)- $N$-methyl- $N$-(pyridin-3-ylmethyl)propanamide $(33 g)(0.022 \mathrm{~g}, 57 \%){ }^{1} \mathrm{H}$ NMR $\left(500 \mathrm{MHz}\right.$, DMSO- $\left.d_{6}, 80^{\circ} \mathrm{C}\right) \delta 8.43(\mathrm{~s}, 1 \mathrm{H}), 8.13(\mathrm{~s}, 1 \mathrm{H}), 8.01(\mathrm{~s}, 1 \mathrm{H}), 7.93(\mathrm{~d}, J=7.6 \mathrm{~Hz}, 1 \mathrm{H}), 7.55(\mathrm{~d}, J=7.8$ $\mathrm{Hz}, 1 \mathrm{H}), 7.42$ (t, $J=7.6 \mathrm{~Hz}, 1 \mathrm{H}), 7.36$ (d, $J=7.3 \mathrm{~Hz}, 2 \mathrm{H}), 7.29$ (s, 2H), 6.78 (s, 2H), 4.54 (s, 2H), 3.27 (s, 3H), 2.98 $(\mathrm{t}, J=7.5 \mathrm{~Hz}, 2 \mathrm{H}), 2.77$ (t, $J=7.5 \mathrm{~Hz}, 2 \mathrm{H}) .{ }^{13} \mathrm{C}$ NMR $\left(126 \mathrm{MHz}, \mathrm{DMSO}-d_{6}, 80^{\circ} \mathrm{C}\right) \delta 171.73,152.27,149.09,148.05$, $142.03,135.14,129.96,129.58,128.69,126.26,123.94,123.36,109.43,47.95,34.87,33.65,30.51$. HRMS (ESITOF) calcd for $\mathrm{C}_{21} \mathrm{H}_{22} \mathrm{~N}_{7} \mathrm{O}[\mathrm{M}+\mathrm{H}]^{+} 388.1886$, found 388.1877 .

3-(3-(6-amino-9H-purin-8-yl)phenyl)- $N$-methyl- $N$-((4-oxo-3,4-dihydrothieno[3,2- $d]$ pyrimidin-2yl)methyl)propanamide (33h) $(0.045 \mathrm{~g}, 84 \%){ }^{1} \mathrm{H}$ NMR $\left(500 \mathrm{MHz}, \mathrm{DMSO}-d_{6}, 80^{\circ} \mathrm{C}\right) \delta 11.80(\mathrm{~s}, 1 \mathrm{H}), 8.13(\mathrm{~s}, 1 \mathrm{H})$, $8.04(\mathrm{~d}, J=5.2 \mathrm{~Hz}, 1 \mathrm{H}), 8.02-7.95$ (m, 2H), 7.90 (s, 1H), 7.40 (d, $J=10.5 \mathrm{~Hz}, 2 \mathrm{H}), 7.26$ (d, $J=5.3 \mathrm{~Hz}, 1 \mathrm{H}), 6.75$ (s, 2H), 4.49 (s, 2H), 3.12 (s, 3H), 2.96 (t, $J=7.6 \mathrm{~Hz}, 2 \mathrm{H}), 2.79$ (bs, $2 \mathrm{H}) .{ }^{13} \mathrm{C}$ NMR (126 MHz, DMSO-d $) \delta 171.11$, 152.37, 142.21, 139.41, 138.10, 134.84, 130.11, 129.53, 128.82, 127.23, 126.38, 124.91, 124.05, 121.95, 49.65, 33.72, 31.95, 30.48. HRMS (ESI-TOF) calcd for $\mathrm{C}_{22} \mathrm{H}_{21} \mathrm{~N}_{8} \mathrm{O}_{2} \mathrm{~S}[\mathrm{M}+\mathrm{H}]^{+} 461.1508$, found 461.1494 .

3-(3-(6-amino-9H-purin-8-yl)phenyl)- $N$-methyl- $N$-((4-oxo-3,4-dihydroquinazolin-2-yl)methyl)propanamide (33i) $(0.039 \mathrm{~g}, 52 \%){ }^{1} \mathrm{H}$ NMR $\left(500 \mathrm{MHz}\right.$, DMSO- $\left.d_{6}, 80^{\circ} \mathrm{C}\right) \delta 11.79(\mathrm{~s}, 1 \mathrm{H}), 8.10(\mathrm{~d}, J=7.8 \mathrm{~Hz}, 1 \mathrm{H}), 7.77(\mathrm{t}, J=7.7$ $\mathrm{Hz}, 1 \mathrm{H}), 7.65$ (s, 3H), 7.58 (d, $J=8.2 \mathrm{~Hz}, 2 \mathrm{H}), 7.47$ (t, $J=7.5 \mathrm{~Hz}, 1 \mathrm{H}), 7.33-7.14$ (m, 4H), 4.47 (s, 2H), 3.12 (s, $3 \mathrm{H}), 2.87(\mathrm{t}, J=7.8 \mathrm{~Hz}, 2 \mathrm{H}), 2.72(\mathrm{t}, J=7.7 \mathrm{~Hz}, 2 \mathrm{H}) .{ }^{13} \mathrm{C}$ NMR $\left(126 \mathrm{MHz}, \mathrm{DMSO}-d_{6}, 80^{\circ} \mathrm{C}\right) \delta 172.87,160.05,152.42$, $142.29,135.94,134.42,130.23,129.55,128.92,127.87,126.85,126.43,125.79,124.12,121.09,115.73,59.64,36.55$, 33.79, 30.45. HRMS (ESI-TOF) calcd for $\mathrm{C}_{24} \mathrm{H}_{23} \mathrm{~N}_{8} \mathrm{O}_{2}[\mathrm{M}+\mathrm{H}]^{+} 455.1944$, found 455.1950 .

$\boldsymbol{N}$-([1,2,4]triazolo[4,3-a]pyridin-3-ylmethyl)-3-(3-(6-amino-9H-purin-8-yl)phenyl)- $N$-methylpropanamide (33j) $(0.029 \mathrm{~g}, 73 \%){ }^{1} \mathrm{H}$ NMR $\left(500 \mathrm{MHz}\right.$, DMSO- $\left.d_{6}, 80^{\circ} \mathrm{C}\right) \delta 8.36(\mathrm{~d}, J=7.0 \mathrm{~Hz}, 1 \mathrm{H}), 8.13(\mathrm{~s}, 1 \mathrm{H}), 7.97(\mathrm{~s}, 1 \mathrm{H}), 7.89(\mathrm{~d}, J$ $=7.6 \mathrm{~Hz}, 1 \mathrm{H}), 7.68(\mathrm{~d}, J=9.3 \mathrm{~Hz}, 1 \mathrm{H}), 7.41-7.27(\mathrm{~m}, 4 \mathrm{H}), 6.90(\mathrm{t}, J=6.4 \mathrm{~Hz}, 1 \mathrm{H}), 6.76(\mathrm{~s}, 2 \mathrm{H}), 5.03(\mathrm{~s}, 2 \mathrm{H}), 3.00$ $(\mathrm{s}, 3 \mathrm{H}), 2.96$ (t, $J=7.6 \mathrm{~Hz}, 2 \mathrm{H}), 2.78(\mathrm{~s}, 2 \mathrm{H}) .{ }^{13} \mathrm{C} \mathrm{NMR}\left(126 \mathrm{MHz}, \mathrm{DMSO}-d_{6}, 80^{\circ} \mathrm{C}\right) \delta 172.87,152.86,150.10,143.94$, 142.48, 130.52, 130.05, 129.26, 128.22, 126.82, 124.54, 124.39, 115.57, 114.06, 40.97, 35.17, 34.19, 30.90.HRMS (ESI-TOF) calcd for $\mathrm{C}_{22} \mathrm{H}_{22} \mathrm{~N}_{9} \mathrm{O}[\mathrm{M}+\mathrm{H}]^{+} 428.1947$, found 428.1961 . 
Table S1. A sequence alignment produced by Prime, of two human DNMT3 proteins (Q9UBC3 and 2QRV_A). 76\% identities (fraction of amino acids that are the same between a pair of sequences after their alignment). P (proline) and C (cysteine) catalytic site. Green area corresponds to the active-site loop. Red area represents loop area that is not defined.

\begin{tabular}{|c|c|c|c|c|c|c|c|c|c|c|c|c|c|c|c|c|c|c|c|c|c|c|c|c|c|c|c|c|c|c|c|c|c|c|c|}
\hline Q9UBC3 & $\mathrm{P}$ & A & A & $\mathrm{R}$ & $\mathrm{R}$ & $\mathrm{R}$ & $\mathrm{P}$ & I & $\mathrm{R}$ & V & $\mathrm{L}$ & $S$ & $\mathrm{~L}$ & $\mathrm{~F}$ & $\mathrm{D}$ & G & I & A & $\mathrm{T}$ & G & $\mathrm{Y}$ & $\mathrm{L}$ & V & $\mathrm{L}$ & $\mathrm{K}$ & $\mathrm{E}$ & $\mathrm{L}$ & $\mathrm{G}$ & I & $\mathrm{K}$ & V & G & $\mathrm{K}$ & $\mathrm{Y}$ & 601 \\
\hline 2QRV_A & $\mathrm{P}$ & A & E & $\mathrm{K}$ & $\mathrm{R}$ & K & $\mathrm{P}$ & I & $\mathrm{R}$ & V & $\mathrm{L}$ & $\mathrm{S}$ & $\mathrm{L}$ & $\mathrm{F}$ & D & G & I & A & $\mathrm{T}$ & G & $\mathrm{L}$ & $\mathrm{L}$ & V & $\mathrm{L}$ & K & D & $\mathrm{L}$ & G & I & Q & V & D & $\mathrm{R}$ & Y & \\
\hline Q9UBC3 & V & A & $S$ & $\mathrm{E}$ & $\mathrm{V}$ & $\mathrm{C}$ & $\mathrm{E}$ & $\mathrm{E}$ & $\mathrm{S}$ & I & A & V & $\mathrm{G}$ & $\mathrm{T}$ & V & $\mathrm{K}$ & $\mathrm{H}$ & $\mathrm{E}$ & G & $\mathrm{N}$ & I & $\mathrm{K}$ & $\mathrm{Y}$ & V & $\mathrm{N}$ & $\mathrm{D}$ & $\mathrm{V}$ & $\mathrm{R}$ & $\mathrm{N}$ & I & $\mathrm{T}$ & $\mathrm{K}$ & $\mathrm{K}$ & $\mathrm{N}$ & 635 \\
\hline 2QRV_A & I & A & S & E & V & $\mathrm{C}$ & $\mathrm{E}$ & D & S & I & $\mathrm{T}$ & V & G & M & V & $\mathrm{R}$ & $\mathrm{H}$ & Q & G & K & I & M & $\mathrm{Y}$ & V & G & D & V & $\mathrm{R}$ & S & V & $\mathrm{T}$ & Q & $\mathrm{K}$ & $\mathrm{H}$ & \\
\hline Q9UBC3 & I & $E$ & $\mathrm{E}$ & W & $\mathrm{G}$ & $P$ & $\mathrm{~F}$ & D & $\mathrm{L}$ & V & I & G & G & $\mathrm{S}$ & $\mathrm{P}$ & $\mathrm{C}$ & $\mathrm{N}$ & $\mathrm{D}$ & $\mathrm{L}$ & S & $\mathrm{N}$ & $\mathrm{V}$ & $\mathrm{N}$ & $\mathrm{P}$ & A & $\mathrm{R}$ & $\mathrm{K}$ & G & $\mathrm{L}$ & $\mathrm{Y}$ & E & G & $\mathrm{T}$ & G & 669 \\
\hline Q9UBC3 & $\mathrm{R}$ & $\mathrm{L}$ & $\mathrm{F}$ & $\mathrm{F}$ & E & $\mathrm{F}$ & Y & $\mathrm{H}$ & $\mathrm{L}$ & $\mathrm{L}$ & $\mathrm{N}$ & $\mathrm{Y}$ & $\mathrm{S}$ & $\mathrm{R}$ & $\mathrm{P}$ & $\mathrm{K}$ & $\mathrm{E}$ & $\mathrm{G}$ & D & $\mathrm{D}$ & $\mathrm{R}$ & $\mathrm{P}$ & $\mathrm{F}$ & $\mathrm{F}$ & $\mathrm{W}$ & $\mathrm{M}$ & $\mathrm{F}$ & $\mathrm{E}$ & $\mathrm{N}$ & $\mathrm{V}$ & $\mathrm{V}$ & A & $\mathrm{M}$ & $\mathrm{K}$ & 703 \\
\hline 2QRV_A & $\mathrm{R}$ & $\mathrm{L}$ & $\mathrm{F}$ & F & E & F & Y & $\mathrm{R}$ & $\mathrm{L}$ & $\mathrm{L}$ & $\mathrm{H}$ & D & A & $\mathrm{R}$ & $\mathrm{P}$ & $\mathrm{K}$ & E & G & D & D & $\mathrm{R}$ & $\mathrm{P}$ & $\mathrm{F}$ & $\mathrm{F}$ & $\mathrm{W}$ & $\mathrm{L}$ & F & E & $\mathrm{N}$ & V & V & A & M & G & \\
\hline Q9UBC3 & V & G & D & $\mathrm{K}$ & $\mathrm{R}$ & $\mathrm{D}$ & I & $\mathrm{S}$ & $\mathrm{R}$ & $\mathrm{F}$ & $\mathrm{L}$ & $\mathrm{E}$ & $\mathrm{C}$ & $\mathrm{N}$ & $P$ & $\mathrm{~V}$ & M & I & D & A & I & K & V & $\mathrm{S}$ & A & A & $\mathrm{H}$ & $\mathrm{R}$ & A & $\mathrm{R}$ & $\mathrm{Y}$ & $\mathrm{F}$ & $\mathrm{W}$ & G & 737 \\
\hline 2QRV_A & V & S & D & $\mathrm{K}$ & $\mathrm{R}$ & D & I & $\mathrm{S}$ & $\mathrm{R}$ & $\mathrm{F}$ & $\mathrm{L}$ & E & S & $\mathrm{N}$ & $\mathrm{P}$ & V & M & I & D & A & $\mathrm{K}$ & $\mathrm{E}$ & V & S & A & A & $\mathrm{H}$ & $\mathrm{R}$ & A & $\mathrm{R}$ & Y & $\mathrm{F}$ & W & G & \\
\hline 2QRV_A & $\mathrm{N}$ & $\mathrm{P}$ & $\mathrm{L}$ & G & M & $\mathrm{N}$ & $\mathrm{R}$ & $\mathrm{P}$ & $\mathrm{L}$ & A & S & $\mathrm{T}$ & V & $\mathrm{N}$ & D & $\mathrm{K}$ & $\mathrm{L}$ & $\mathrm{E}$ & $\mathrm{L}$ & Q & $\mathrm{E}$ & $\mathrm{C}$ & $\mathrm{L}$ & $\mathrm{E}$ & $\mathrm{H}$ & G & $\mathrm{R}$ & I & A & $\mathrm{K}$ & F & S & $\mathrm{K}$ & $\mathrm{V}$ & \\
\hline Q9UBC3 & Q & $\mathrm{T}$ & I & $\mathrm{T}$ & $\mathrm{T}$ & K & $S$ & $\mathrm{~N}$ & S & I & $\mathrm{K}$ & Q & G & K & $\mathrm{N}$ & Q & L & $\mathrm{F}$ & $\mathrm{P}$ & $\mathrm{V}$ & $\mathrm{V}$ & M & $\mathrm{N}$ & G & $\mathrm{K}$ & $\mathrm{E}$ & $\mathrm{D}$ & V & $\mathrm{L}$ & $\mathrm{W}$ & $\mathrm{C}$ & $\mathrm{T}$ & $\mathrm{E}$ & $\mathrm{L}$ & 805 \\
\hline 2QRV_A & $\mathrm{R}$ & $\mathrm{T}$ & I & $\mathrm{T}$ & $\mathrm{T}$ & $\mathrm{R}$ & S & $\mathrm{N}$ & $S$ & I & K & Q & G & K & D & Q & $\mathrm{H}$ & $\mathrm{F}$ & $\mathrm{P}$ & $\mathrm{V}$ & $\mathrm{F}$ & M & $\mathrm{N}$ & $\mathrm{E}$ & $\mathrm{K}$ & $\mathrm{E}$ & $\mathrm{D}$ & I & $\mathrm{L}$ & $\mathrm{W}$ & $\mathrm{C}$ & $\mathrm{T}$ & $\mathrm{E}$ & M & \\
\hline Q9UBC3 & $\mathrm{E}$ & $\mathrm{R}$ & I & $\mathrm{F}$ & G & $\mathrm{F}$ & $\mathrm{P}$ & V & $\mathrm{H}$ & Y & $\mathrm{T}$ & D & V & S & $\mathrm{N}$ & M & G & $\mathrm{R}$ & G & A & $\mathrm{R}$ & Q & $\mathrm{K}$ & $\mathrm{L}$ & $\mathrm{L}$ & G & $\mathrm{R}$ & S & W & $\mathrm{S}$ & V & $\mathrm{P}$ & $\mathrm{V}$ & I & 839 \\
\hline 2QRV_A & $\mathrm{E}$ & $\mathrm{R}$ & V & $\mathrm{F}$ & G & $\mathrm{F}$ & $\mathrm{P}$ & V & $\mathrm{H}$ & $\mathrm{Y}$ & $\mathrm{T}$ & D & V & $\mathrm{S}$ & $\mathrm{N}$ & M & S & $\mathrm{R}$ & $\mathrm{L}$ & A & $\mathrm{R}$ & Q & $\mathrm{R}$ & $\mathrm{L}$ & $\mathrm{L}$ & G & $\mathrm{R}$ & $S$ & W & $\mathrm{S}$ & V & $\mathrm{P}$ & V & I & \\
\hline Q9UBC3 & $\mathrm{R}$ & $\mathrm{H}$ & $\mathrm{L}$ & $\mathrm{F}$ & A & $\mathrm{P}$ & $\mathrm{L}$ & K & $\mathrm{D}$ & Y & $\mathrm{F}$ & A & $\mathrm{C}$ & $\mathrm{E}$ & & & & & & & & & & & & & & & & & & & & & \\
\hline 2QRV_A & $\mathrm{R}$ & $\mathrm{H}$ & $\mathrm{L}$ & $\mathrm{F}$ & A & $\mathrm{P}$ & $\mathrm{L}$ & K & $\mathrm{E}$ & Y & $\mathrm{F}$ & A & $\mathrm{C}$ & V & & & & & & & & & & & & & & & & & & & & & \\
\hline
\end{tabular}


Table S2. Molecular weight, xlogP, rotatable bonds (RB), hydrogen bond acceptors and donors (HBA) (HBD), docking scores and ranks of the hits tested experimentally. The corresponding docking rank is shown in parenthesis.

\begin{tabular}{|c|c|c|c|c|c|c|c|c|c|}
\hline JLD & ZINC\# & CAS\# & MW & $\mathrm{x} \log \mathrm{P}$ & $\mathrm{RB}$ & HBA & HBD & Glide XP (rank) & Supplier \\
\hline 1 & 25171563 & $1241214-68-5$ & 376.4 & 2.22 & 7 & 7 & 1 & $-11.86(3)$ & Enamine Z362662154 \\
\hline 2 & 14391809 & $1197925-52-2$ & 443.5 & 1.29 & 5 & 9 & 0 & $-11.48(11)$ & Enamine Z28036288 \\
\hline 3 & 14228671 & $940783-42-6$ & 458.6 & 1.75 & 5 & 8 & 0 & $-10.92(57)$ & Enamine Z147055482 \\
\hline 4 & 09494447 & $879337-26-5$ & 451.5 & 2.58 & 4 & 8 & 0 & $-10.76(122)$ & Enamine Z15399776 \\
\hline 5 & 11331166 & $949245-37-8$ & 390.4 & 1.11 & 6 & 9 & 1 & $-10.74(130)$ & Enamine Z223672454 \\
\hline 6 & 08614046 & $931969-32-3$ & 375.8 & 3.02 & 7 & 7 & 2 & $-10.54(294)$ & Chem Div D264-0818 \\
\hline 7 & 12531405 & 931632-94-9 & 388.5 & 1.92 & 6 & 6 & 1 & $-10.51(327)$ & Enamine Z101589232 \\
\hline 8 & 47014625 & $1280878-06-9$ & 368.5 & 0.37 & 6 & 6 & 1 & $-10.27(740)$ & Enamine Z423065738 \\
\hline 9 & 55346958 & $1252097-33-8$ & 367.4 & 1.46 & 7 & 7 & 2 & $-10.23(847)$ & Enamine Z809130570 \\
\hline $10^{\mathrm{a}}$ & 20231915 & $1034584-26-3$ & 473.6 & 1.94 & 7 & 9 & 2 & $-11.09(24)$ & Chem Div C450-0086 \\
\hline $11^{\mathrm{a}}$ & 21655126 & $1032001-78-7$ & 499.5 & 3.49 & 5 & 10 & 1 & $-10.26(767)$ & Chem Div L859-0485 \\
\hline 12 & 04753819 & $898125-98-9$ & 403.8 & 2.19 & 6 & 8 & 1 & $-11.07(30)$ & Amb 1086172 \\
\hline 13 & 31776613 & $1211343-29-1$ & 383.4 & 2.80 & 5 & 7 & 1 & $-10.71(152)$ & Amb10721455 \\
\hline 14 & 05988166 & $356587-96-7$ & 357.4 & 3.07 & 6 & 7 & 2 & $-10.49(351)$ & Amb 1930321 \\
\hline 15 & 63772470 & $1228552-97-3$ & 225.6 & -0.73 & 2 & 4 & 1 & $-10.85(80)$ & Amb16186884 \\
\hline $16^{\mathrm{b}}$ & 31776635 & $1197699-86-7$ & 397.5 & 3.18 & 5 & 7 & 1 & & Amb 10721456 \\
\hline $17^{\mathrm{c}}$ & 15022385 & 898125-99-0 & 465.9 & 3.46 & 7 & 8 & 1 & & Amb 1086173 \\
\hline $18^{\mathrm{d}}$ & 23873211 & 919938-61-7 & 486.6 & 2.35 & 5 & 8 & 0 & -9.14 & Amb 19397409 \\
\hline $19^{c}$ & 09236083 & $878724-96-0$ & 417.9 & 2.56 & 7 & 8 & 1 & & Amb 2031987 \\
\hline \multicolumn{10}{|l|}{$20^{\mathrm{e}}$} \\
\hline \multicolumn{10}{|l|}{$021^{\mathrm{e}}$} \\
\hline $022^{\mathrm{e}}$ & & & & & & & & & \\
\hline
\end{tabular}

(a) Compounds selected from GOLD Docking results (b) analog of JLD013, (c) analog of JLD012, (d) analog of JLD003, (e) Synthesized compounds. 


\section{References}

(1) Jia, D.; Jurkowska, R. Z.; Zhang, X.; Jeltsch, A.; Cheng, X. Structure of DNMT3a bound to DMLT3L suggests a model for de novo DNA methylation. Nature 2007, 449, 248-251.

(2) Prime, Schrödinger, LLC, New York, NY, 2019.

(3) Kaminski, G. A.; Friesner, R. A.; Tirado-Rives, J.; Jorgensen, W. L. Evaluation and Reparametrization of the OPLS-AA Force Field for Proteins via Comparison with Accurate Quantum Chemical Calculations on Peptides. $J$. Phys. Chem. B 2001, 105, 6474-6487.

(4) Irwin, J. J.; Shoichet, B. K. ZINC—a free database of commercially available compounds for virtual screening. $J$. Chem. Inf. Model 2005, 45, 177-182.

(5) Lipinski, C. A.; Lombardo, F.; Dominy, B. W.; Feeney, P. J. Experimental and Computational Approaches to Estimate Solubility and Permeability in Drug Discovery and Development Settings. Adv. Drug Deliv. Rev. 2001, 46, $3-26$.

(6) Friesner, R. A.; Banks, J. L.; Murphy, R. B.; Halgren, T. A.; Klicic, J. J.; Mainz, D. T.; Repasky, M. P.; Knoll, E. H.; Shelley, M.; Perry, J. K.; Shaw, D. E.; Francis, P.; Shenkin, P. S. Glide: anew approach for rapid, accurate docking and scoring. 1. Method and assessment of docking accuracy. J. Med. Chem. 2004, 47, 1739-1749.

(7) Jones, G.; Willett, P.; Glen, R. C.; Glen, R. C.; Leach, A. R.; Taylor, R. Development and validation of a genetic algorithm for flexible docking. J. Mol. Biol. 1997, 267, 727-748.

(8) Friesner, R. A.; Murphy, R. B.; Repasky, M. P.; Frye, L. L.; Greenwood, J. R.; Halgren, T. A.; Sanschagrin, P. C.; Mainz, D. T. Extra precision glide: docking and scoring incorporating a model of hydrophobic enclosure for proteinligand complexes. J. Med. Chem. 2006, 49, 6177-6196.

(9) QikProp, Schrödinger, LLC, New York, NY, 2006.

(10) Wood, R. J.; McKelvie, J. C.; Maynard-Smith, M. D.; Roach, P. L. A real-time assay for CpG-specific cytosineC5 methyltransferase activity. Nucleic Acids Res. 2010, 38, e107.

(11) Syeda, F.; Fagan, R. L.; Wean, M.; Avvakumov, G. V.; Walker, J. R.; Xue, S.; Dhe-Paganon, S.; Brenner, C. The replication focus targeting sequence (RFTS) domain is a DNA-competitive inhibitor of DNMT1. J. Biol. Chem. 2011, 286, 15344-15351.

(12) Fagan, R. L.; Wu, M.; Chédin, F.; Brenner, C. Ana ultrasensitive high throughput screen for DNA methyltransferase 1 - targeted molecular probes. PLos One 2013, 13, e78752.

(13) Berman, J.; Schmid, M.; Mendlein, J.; Kaplan, N. Compositions comprising multiple bioactive agents, and methods of using the same. 2006 U.S. Patent 20060142265-A1.

(14) Xin, Z.; Liu, G.; Pei, Z.; Szczepankiewicz, B.; Serby, M.; Zhao, H. Protein-tyrosine phosphatase inhibitors and uses thereof. 2004 U.S. Patent 20040167188-A1.

(15) Joucia, L.; Batail, N.; Djakovitch, L. "On water" direct and site-selective Pd-catalysed C-H arylation of (NH)indoles. Adv. Synth. Catal. 2010, 352, 17, 2929-2936.

(16) Mothana, S.; Grassot, J.-M.; Hall, D. G. Multistep phase-switch synthesis by using liquid-liquid partitioning of boronic acids: productive tags with an expanded repertoire of compatible reactions. Angew. Chem. Int. Ed. 2010, 49, $16,2883-2887$.

(17) Work-up from Beshore, D. C.; Dudkin, V.; Garbaccio, R. M.; Johnson, A. W.; Kuduk, S. D.; Skudlarek, J. W.; Wang, C.; Fraley, M. E. Ether benzotriazole derivatives. U.S. Patent 20120135977-A1, 2012.

(18) Kudo, N.; Perseghini, M.; Fu, G. C. A versatile method for Suzuki cross-coupling reactions of nitrogen heterocycles. Angew. Chem. Int. Ed. 2006, 45, 1282-1284. 